This document is the Accepted Manuscript version of a Published Work that appeared in final form in ACS Catalysis, copyright (C) American Chemical Society after peer review and technical editing by the publisher. To access the final edited and published work see https://pubs.acs.org/doi/abs/10.1021/acscatal.7b04431

\title{
Mechanism of Ethylene Oxychlorination on Ceria
}

\author{
Matthias Scharfe, ${ }^{\dagger}$ Marçal Capdevila-Cortada, ${ }^{\ddagger}$ Vita A. Kondratenko, ${ }^{\S}$ Evgenii V. Kondratenko, ${ }^{\S}$ \\ Sara Colussi," Alessandro Trovarelli, ${ }^{\| \odot ~ N u ́ r i a ~ L o ́ p e z, ~}{ }^{*}, \oplus$ and Javier Pérez-Ramírez ${ }^{* \dagger \odot}$
'Institute for Chemical and Bioengineering, Department of Chemistry and Applied Biosciences, ETH Zurich, Vladimir-Prelog-Weg 1, 8093 Zurich, Switzerland
"Institute of Chemical Research of Catalonia (ICIQ), The Barcelona Institute of Science and Technology, Av. Països Catalans 16, 43007 Tarragona, Spain
${ }^{\S}$ Leibniz-Institut für Katalyse e. V., Albert-Einstein-Straße 29a, 18059 Rostock, Germany
"Dipartimento Politecnico, Università di Udine, via del Cotonificio 108, 33100 Udine, Italy

Supporting Information

ABSTRACT: Ethylene oxychlorination on $\mathrm{CeO}_{2}$ provides ethylene dichloride (EDC) and the desired vinyl chloride (VCM) in a single operation, in contrast to the traditional process that requires two separate units. The origin of this outstanding performance is unclear, and the mechanism has not been discussed in detail. In the present work, we combine density functional theory (DFT) with steady-state experiments and temporal analysis of products (TAP) to close this gap. The catalyst surface is found to contain $\mathrm{CeOCl}$, while the bulk phase is $\mathrm{CeO}_{2}$, regardless of the starting materials $\mathrm{CeCl}_{3}, \mathrm{CeOCl}$, or $\mathrm{CeO}_{2}$. Catalysis by different nanostructures highlights that the $\mathrm{CeO}_{2}(111)$ surface is more active than the (100) surface due to the poisoning of the latter, while the selectivities are comparable.

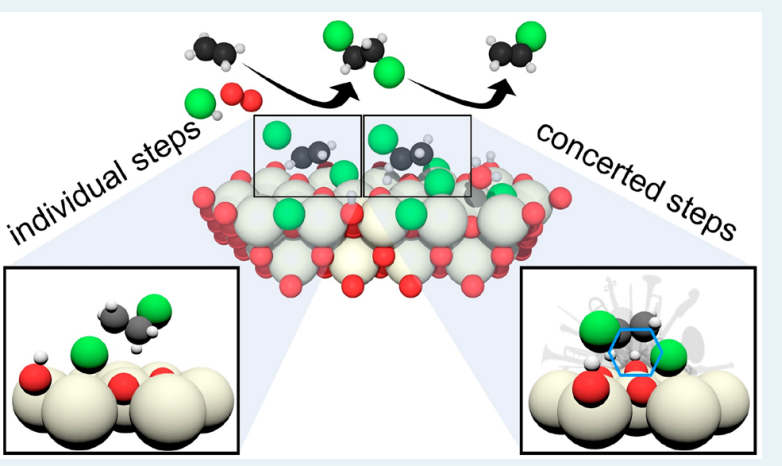
In any case, the degree of oxygen removal from $\mathrm{CeO}_{2}$ and the replenishment of the accordingly formed oxygen vacancies by $\mathrm{Cl}$ and its replenishment by $\mathrm{Cl}$ species lead to increased selectivity to chlorinated products and decreased selectivity to carbon oxides. DFT and TAP studies reveal that the most likely pathway of VCM formation takes place by a cascade reaction. First, EDC appears and then $\mathrm{HCl}$ is extracted in a concerted step to lead to VCM. Such steps are a key characteristic of ceria. Other paths leading to minor products such as 1,2-dichloroethene (DCE) are found possible by starting from VCM or EDC. $\mathrm{CO}$ is formed by combustion of chlorinated species, whereas $\mathrm{CO}_{2}$ can either stem from further oxidation of $\mathrm{CO}$ or directly from ethylene. In summary, our work points out a rich complex behavior of the chemistry of chlorinated compounds on the oxide surface, indicating that concerted steps and cascade reactions are possible for these materials.

KEYWORDS: ethylene oxychlorination, mechanism, $\mathrm{CeO}_{2}$, oxychloride, oxygen vacancies, density functional theory, temporal analysis of products

\section{INTRODUCTION}

Polyvinyl chloride (PVC) constituted a 53 billion USD market in 2015, growing with a compound annual growth rate of 5.3\%. ${ }^{1}$ Its corresponding monomer, vinyl chloride (commonly denoted as VCM), is produced through hydrochlorination of acetylene $^{2-4}$ or through energy-intensive thermal dehydrochlorination of 1,2-dichloroethane (known as ethylene dichloride, EDC) with a low yield of $49-58 \% .^{5}$ EDC is, in turn, formed either by $\mathrm{Cl}_{2}$ addition to ethylene or by ethylene oxychlorination. The latter enables recycling of $\mathrm{HCl}$ from the dehydrochlorination step in the balanced VCM process. ${ }^{5-7}$ To date, the catalyst in ethylene oxychlorination comprises cupric chloride $\left(\mathrm{CuCl}_{2}\right)$ as the active phase, impregnated on a porous support such as alumina, and is promoted by numerous alkali, alkaline-earth, and rare-earth metals to reduce the copper loss and/or improve the activity and selectivity. ${ }^{8-11}$ However, while an EDC selectivity of $99 \%$ is achieved, issues surrounding active phase volatilization or particle stickiness have not yet been fully resolved. ${ }^{12}$ Nevertheless, the mechanism of ethylene oxychlorination on $\mathrm{CuCl}_{2}$-based catalysts has been unveiled by numerous in situ and operando spectroscopy studies. ${ }^{13-17}$ Briefly, the process encompasses a three-step redox mechanism: (i) chlorination of ethylene by reduction of $\mathrm{CuCl}_{2}$ to $\mathrm{CuCl}$, (ii) formation of a cupric oxychloride by oxidation of $\mathrm{CuCl}$, and finally (iii) closure of the catalytic cycle though rechlorination 
of the oxychloride with $\mathrm{HCl}$ and water elimination. $6,9,10,13,14,16,18-26$

Recently, the great potential of $\mathrm{CeO}_{2}$ in ethylene oxychlorination was uncovered, revealing a stable bifunctional character and enabling direct VCM and EDC production with single-step yields up to $25 \% .{ }^{27}$ Some of us put forward that this VCM formation can be attributed to the material acidity, correlating with the EDC dehydrochlorination performance of $\mathrm{CeO}_{2}$, and that higher chlorination leads to higher EDC selectivity and suppressed oxidation routes. ${ }^{27}$ Alternative materials, also based on rare-earth elements, such as $\mathrm{EuOCl}$, were less active but highly selective toward VCM (75\%) and evidenced the selectivity-acidity link. ${ }^{28}$ However, a previous study aiming to shed light on the complex ethylene oxychlorination reaction network on oxide- or oxychloridebased materials used density functional theory (DFT) on $\mathrm{RuO}_{2}$ as a model catalyst due to the simple electronic structure. ${ }^{29}$ $\mathrm{RuO}_{2}$ is a poor oxychlorination catalyst, as it mostly forms $\mathrm{CO}_{2}$ and only small amounts of EDC and VCM during the reaction. Nevertheless, investigation of 34 elementary steps over the relatively simple surface revealed that oxidation processes are thermodynamically favored, whereas chlorination processes are kinetically controlled. ${ }^{29}$ In addition, the surface chlorine uptake, i.e., the chlorine coverage, is a key factor determining the selectivity of $\mathrm{RuO}_{2}$. Only high chlorine coverage allows VCM displacement by $\mathrm{C}_{2} \mathrm{H}_{4}$, thus preventing the formation of VCMderived products; however at the same time it destabilizes $\mathrm{C}_{2} \mathrm{H}_{4} \mathrm{Cl}$ intermediates, favoring the formation of EDC instead of VCM. ${ }^{29}$

In this study, we investigate the mechanism of ethylene oxychlorination over $\mathrm{CeO}_{2}$, as it was the most active under a broad range of conditions and exhibited a strong effect of the feed concentrations of $\mathrm{HCl}$ and $\mathrm{O}_{2}$ on the activity and selectivity to chlorinated products. ${ }^{27,28}$ In addition, $\mathrm{CeO}_{2}$ shows a correlation between dehydrochlorination performance and surface acidity, the exact nature of which is as yet unknown. Even though $\mathrm{CeO}_{2}$ has a more complex electronic structure than $\mathrm{RuO}_{2}$, the computational setup based on $\mathrm{DFT}+U$ has proven reasonably accurate. ${ }^{30-36}$ As our experiments reveal that the active phase in oxychlorination is actually an oxychloride, previous studies of the mechanism of oxychlorination on $\mathrm{RuO}_{2}$ and chlorination of $\mathrm{RuO}_{2}$ and $\mathrm{CeO}_{2}$ in the related $\mathrm{HCl}$ oxidation potentially allow knowledge transfer to this work or accompany our findings. ${ }^{29,32,37-40}$ We prove and complement the theoretical insight by DFT with advanced transient kinetic studies, uncovering the reaction pathways that lead to chlorinecontaining hydrocarbons and suggesting the routes for combustion.

\section{MATERIALS AND METHODS}

2.1. Catalyst Preparation. Commercial $\mathrm{CeO}_{2}$ (SigmaAldrich, $99.5 \%$ ) was calcined at 873 or $1023 \mathrm{~K}$ in static air using a heating rate of $5 \mathrm{~K} \mathrm{~min}^{-1}$ and an isothermal step of $5 \mathrm{~h}$ prior to its use in the catalytic studies. $\mathrm{CeCl}_{3}(\mathrm{ABCR}, 99.9 \%)$ was calcined at $423 \mathrm{~K}$ in static air using a heating rate of $5 \mathrm{~K} \mathrm{~min}^{-1}$ and an isothermal step of $5 \mathrm{~h}$ in order to desorb any adsorbed species, while not transforming it to $\mathrm{CeO}_{2}$. The catalysts are hereafter denoted as $\mathrm{CeCl}_{3} / \mathrm{CeO}_{2}-x(-\mathrm{p} y)(-\mathrm{E} z)$, where $x$ is the calcination temperature in $\mathrm{K}, y$ the prereduction temperature in $\mathrm{K}$ if applied, and $\mathrm{E} z$ indicates the material used in ethylene oxychlorination at a reaction temperature of $z$ in $\mathrm{K}$. CeOCl was prepared by calcination at $1023 \mathrm{~K}$, following the method reported by Farra et al. ${ }^{41} \mathrm{CeO}_{2}$ nanocubes $\left(\mathrm{CeO}_{2}-\mathrm{NC}\right)$ were hydrothermally synthesized, with optimization of procedures reported elsewhere. ${ }^{42-44}$ Briefly, $5.21 \mathrm{~g}$ of $\mathrm{Ce}\left(\mathrm{NO}_{3}\right)_{3} \cdot 6 \mathrm{H}_{2} \mathrm{O}$ was dissolved in $30 \mathrm{~mL}$ of distilled water to which $210 \mathrm{~mL}$ of $6.9 \mathrm{M}$ $\mathrm{NaOH}$ solution was added dropwise under vigorous stirring. After precipitation, the suspension was transferred into a Teflon-lined cylinder, sealed in a stainless-steel autoclave, and kept at $453 \mathrm{~K}$ for $24 \mathrm{~h}$. Subsequently, the suspension was cooled to room temperature, centrifuged, and washed three times with water and ethanol before the product was dried overnight at $333 \mathrm{~K}$ and calcined in static air at $773 \mathrm{~K}$ for $3 \mathrm{~h}$.

2.2. Catalyst Characterization. $\mathrm{N}_{2}$ sorption at $77 \mathrm{~K}$ was measured in a Quantachrome Quadrasorb-SI analyzer. Prior to the measurements, the samples were outgassed to $50 \mathrm{mbar}$ at $573 \mathrm{~K}$ for $12 \mathrm{~h}$. The Brunauer-Emmett-Teller (BET) method was applied to calculate the total surface area, $S_{\text {BET }}$, in $\mathrm{m}^{2} \mathrm{~g}^{-1} \cdot 45$ Oxygen storage capacity (OSC) measurements were performed by thermogravimetric analysis (TGA) on a TA Instruments Q500 apparatus. The sample (30 mg) was loaded on a platinum pan and pretreated in $\mathrm{N}_{2}\left(60 \mathrm{~cm}^{3} \mathrm{STP} \mathrm{min}^{-1}\right)$ at 573 $\mathrm{K}$ for $1 \mathrm{~h}$, then the temperature was ramped up to $673 \mathrm{~K}$ and equilibrated for $15 \mathrm{~min}$. Thereafter, a flow with $4.5 \mathrm{vol} \% \mathrm{H}_{2}$ in $\mathrm{N}_{2}\left(60 \mathrm{~cm}^{3}\right.$ STP $\left.\mathrm{min}^{-1}\right)$ was introduced and maintained for $2 \mathrm{~h}$ (first OSC measurement) before purging with $\mathrm{N}_{2}$ for $5 \mathrm{~min}$ and reoxidizing the sample with air $\left(60 \mathrm{~cm}^{3} \mathrm{STP} \mathrm{min}^{-1}\right)$ for $1 \mathrm{~h}$. After a second purge in $\mathrm{N}_{2}$ for $5 \mathrm{~min}$, a second OSC measurement was performed under identical conditions. Then, two more OSC measurements were performed, following the same procedure in order to ensure that no chlorine removal would impair the measured OSC. The chlorine content in the used samples was estimated by four independent X-ray fluorescence (XRF) spectroscopy measurements using an Orbis PC Micro-EDXRF analyzer with a $\mathrm{Rh}$ source $(35 \mathrm{kV}$, $500 \mu \mathrm{A})$ and a silicon drift detector. A chlorine background signal was determined in four fresh $\mathrm{CeO}_{2}-873$ at 0.3 atom \% and subtracted from all averaged measurements. Powder X-ray diffraction (XRD) was measured using a PANalytical X'Pert PRO-MPD diffractometer and $\mathrm{Cu} \mathrm{K} \alpha$ radiation $(\lambda=0.15418$ $\mathrm{nm})$. The data were recorded in the $10-70^{\circ} 2 \theta$ range with an angular step size of $0.017^{\circ}$ and a continuing time of $0.26 \mathrm{~s}$ per step.

2.3. Catalytic Testing. The steady-state oxychlorination of ethylene was investigated at ambient pressure in a continuousflow fixed-bed reactor (Scheme S1). The setup consists of (i) mass flow controllers to feed $\mathrm{C}_{2} \mathrm{H}_{4}$ (PanGas, 3.5), $\mathrm{HCl}$ (Air Liquide, 2.8, anhydrous), $\mathrm{O}_{2}$ (Messer, $19.96 \%$ in $\mathrm{He}$ ), $\mathrm{He}$ (PanGas, 5.0) as a carrier gas, and Ar (PanGas, 5.0) as an internal standard, (ii) a syringe pump (Nexus 6000, Chemyx) to feed EDC (Fluka, 99.5\%), (iii) a vaporizer operated at $403 \mathrm{~K}$ accommodating a quartz $\mathrm{T}$-connector filled with glass beads to vaporize EDC, (iv) an electrically heated oven hosting a quartz microreactor equipped with a K-type thermocouple whose tip reaches the center of the catalyst bed, (v) downstream heat tracing to avoid any condensation of the reactants and products, and (vi) a gas chromatograph coupled to a mass spectrometer (GC-MS) for online analysis. The effluent stream was neutralized by passing it through an impinging bottle containing an aqueous $\mathrm{NaOH}$ solution $(1 \mathrm{M})$. The catalyst ( $W_{\text {cat }}=0.5 \mathrm{~g}$, particle size $\left.d_{\mathrm{p}}=0.4-0.6 \mathrm{~mm}\right)$ was loaded in the microreactor $(10 \mathrm{~mm}$ inner diameter) and pretreated in $\mathrm{He}$ at $473 \mathrm{~K}$ for $30 \mathrm{~min}$. Thereafter, a total flow $\left(F_{\mathrm{T}}\right)$ of $100 \mathrm{~cm}^{3} \mathrm{STP}$ $\min ^{-1}$ with a composition of $\mathrm{C}_{2} \mathrm{H}_{4}: \mathrm{HCl}: \mathrm{O}_{2}: \mathrm{Ar}: \mathrm{He}=3:(1-6)$ : (1-6):3:(83.2-90), where Ar acted as internal standard and $\mathrm{He}$ was used as carrier gas, was fed to the reactor at a bed 
temperature $(T)$ of $423-773 \mathrm{~K}$ and pressure $(\mathrm{P})$ of 1 bar. Note that relatively low feed concentrations were selected to prevent corrosion, enable safe handling, and minimize the formation of hot spots in the catalyst bed due to the high reaction exothermicity. The standard $\mathrm{C}_{2} \mathrm{H}_{4}: \mathrm{HCl}: \mathrm{O}_{2}: \mathrm{He}=3: 4.8: 3: 89.2$ feed was chosen on the basis of the literature. ${ }^{12,27}$ Prior to the analysis of the reaction mixtures, the catalysts were equilibrated for at least $1 \mathrm{~h}$ under each condition. The gas composition at the reactor outlet, containing reactants $\left(\mathrm{C}_{2} \mathrm{H}_{4}, \mathrm{O}_{2}, \mathrm{HCl}\right)$ and products (EDC, VCM, DCE, EC, $\mathrm{CO}, \mathrm{CO}_{2}$ ), was determined online using a gas chromatograph equipped with a GSCarbonPLOT column coupled to a mass spectrometer (Agilent GC 7890B, Agilent MSD 5977A) with a triple-axis detector and an electron multiplier. A representative chromatogram is depicted as an inset in Scheme S1. In the $\mathrm{HCl}$ oxidation tests, the $\mathrm{Cl}_{2}$ production was quantified by offline iodometric titration (using a Mettler Toledo G20 Compact Titrator) of triiodide, formed by purging the $\mathrm{Cl}_{2}$-containing reactor outlet through an aqueous KI (Sigma-Aldrich, 99.5\%) solution (0.1 $\mathrm{M}$ ), with $0.01 \mathrm{M}$ sodium thiosulfate solution (Sigma-Aldrich, 99.99\%). The conversion of $\mathrm{HCl}$ in $\mathrm{HCl}$ oxidation experiments, $X(\mathrm{HCl})$, was calculated using eq 1

$$
X(\mathrm{HCl})=\frac{2 x_{\mathrm{Cl}_{2} \text {,outlet }}}{x_{\mathrm{HCl} \text {,inlet }}} \times 100 \%
$$

where $x_{\mathrm{HCl} \text {,inlet }}$ and $x_{\mathrm{Cl}_{2} \text {,outlet }}$ denote the volumetric concentration of $\mathrm{HCl}$ and $\mathrm{Cl}_{2}$ at the reactor inlet and outlet, respectively. The conversion of ethylene in ethylene oxychlorination experiments, $X\left(\mathrm{C}_{2} \mathrm{H}_{4}\right)$, was calculated according to eq 2

$$
X\left(\mathrm{C}_{2} \mathrm{H}_{4}\right)=\frac{x_{\mathrm{C}_{2} \mathrm{H}_{4} \text {,inlet }}-x_{\mathrm{C}_{2} \mathrm{H}_{4} \text {,outlet }}}{x_{\mathrm{C}_{2} \mathrm{H}_{4} \text {, inlet }}} \times 100 \%
$$

where $x_{\mathrm{C}_{2} \mathrm{H}_{4} \text {,inlet }}$ and $x_{\mathrm{C}_{2} \mathrm{H}_{4} \text {,outlet }}$ denote the volumetric concentration of ethylene at the reactor inlet and outlet, respectively. The selectivity of a reaction product $j, S(j)$, was calculated according to eq 3

$$
S(j)=\frac{x_{j} / n_{j}}{\sum x_{j} / n_{j}} \times 100 \%
$$

where $x_{j}$ and $n_{j}$ denote the volumetric concentrations of product $j$ at the reactor outlet and the corresponding stoichiometric factor with respect to the number of carbon atoms, respectively (e.g., $\mathrm{C}_{2} \mathrm{H}_{4}+2 \mathrm{O}_{2} \rightarrow 2 \mathrm{CO}+2 \mathrm{H}_{2} \mathrm{O}, n_{\mathrm{CO}}=$ 2).

The carbon mass balance error $\varepsilon_{\mathrm{C}}$ was determined using eq 4

$$
\varepsilon_{\mathrm{C}}=\left|\frac{x_{\mathrm{C}_{2} \mathrm{H}_{4}, \mathrm{j}, \text { inlet }}-\sum x_{\mathrm{C}_{2} \mathrm{H}_{4}, \mathrm{j} \text {,outlet }} / n_{\mathrm{C}_{2} \mathrm{H}_{4}, \text {, outlet }}}{x_{\mathrm{C}_{2} \mathrm{H}_{4}, \text { inlet }}}\right| \times 100 \%
$$

where $x_{\mathrm{C}_{2} \mathrm{H}_{4} \mathrm{j}}$ and $n_{\mathrm{C}_{2} \mathrm{H}_{4} \mathrm{j}}$ denote the concentration of ethylene or product $j$ at the reactor inlet or outlet and the corresponding stoichiometric factor with respect to the number of carbon atoms, respectively. Each catalytic data point reported is an average of at least three measurements. The carbon mass balance in all catalytic tests closed at $96 \%$ or higher. After the tests, the catalyst bed was quenched to room temperature in $\mathrm{He}$ flow.

2.4. Temporal Analysis of Products. Overall reaction pathways of product formation in ethylene oxychlorination over an equilibrated catalyst sample $\left(\mathrm{CeO}_{2}-873-\mathrm{E} 673\right)$ were studied by temporal analysis of products (TAP), a transient pulse technique with a time resolution of approximately $100 \mu \mathrm{s} .{ }^{46-48}$ The used TAP-2 system is equipped with an in-housedeveloped quartz-tube fixed-bed reactor $\left(d_{\text {in }}=6 \mathrm{~mm}, L=40\right.$ $\mathrm{mm})$ in which the catalyst $\left(W_{\text {cat }}=65 \mathrm{mg}\right.$, particle size $d_{\mathrm{p}}=0.3-$ $0.5 \mathrm{~mm}$ ) was packed between two layers of quartz of the same particle size within the isothermal zone of the reactor. Then, the reactor was evacuated stepwise to $10^{-5} \mathrm{~Pa}$. The pulse experiments were carried out at 673,723 , and $773 \mathrm{~K}$ using $\mathrm{C}_{2} \mathrm{H}_{4}: \mathrm{Ne}=1: 1, \mathrm{C}_{2} \mathrm{H}_{4}: \mathrm{O}_{2}: \mathrm{Ne}=1: 1: 1, \mathrm{HCl}: \mathrm{Ar}=1: 1, \mathrm{Cl}_{2}: \mathrm{Ar}=$ $1: 1$, and $\mathrm{C}_{2} \mathrm{H}_{4} \mathrm{Cl}_{2}: \mathrm{Ar}=1: 6$ mixtures. An overall pulse size was around $10^{16}$ molecules. $\mathrm{Ne}$ (Linde Gas, 5.0), Ar (Linde Gas, 5.0), $\mathrm{O}_{2}$ (Air Liquide, 4.8), $\mathrm{C}_{2} \mathrm{H}_{4}$ (Air Liquide, 3.5), EDC (Sigma-Aldrich, 99.8\%), and $\mathrm{HCl}$ (Air Liquide, 4.5, anhydrous) were used for preparing reaction mixtures without additional purification. A quadrupole mass spectrometer (HAL RC 301 Hiden Analytical) was used for quantitative analysis of feed components and reaction products, where the following AMUs were assigned for mass spectrometric compound identification: $70\left(\mathrm{Cl}_{2}\right), 66$ (EC), 64 (EC, EDC, VCM), 62 (EDC, VCM), 49 $(\mathrm{EDC}), 44\left(\mathrm{CO}_{2}\right), 36(\mathrm{HCl}), 32\left(\mathrm{O}_{2}\right), 29(\mathrm{EC}), 28$ (EC, EDC, $\mathrm{CO}_{2}, \mathrm{CO}, \mathrm{C}_{2} \mathrm{H}_{4}$ ), 27 (EC, EDC, VCM, $\mathrm{C}_{2} \mathrm{H}_{4}$ ), 26 (EC, EDC, VCM, $\left.\mathrm{C}_{2} \mathrm{H}_{4}\right), 22(\mathrm{Ne}), 18\left(\mathrm{H}_{2} \mathrm{O}\right), 2\left(\mathrm{H}_{2} \mathrm{O}, \mathrm{H}_{2}\right), 40(\mathrm{Ar})$ and $20(\mathrm{Ar}, \mathrm{Ne})$. Pulses were repeated 10 times for each AMU and averaged to improve the signal to noise ratio.

2.5. Density Functional Theory. All calculations were performed with periodic boundary conditions at the density functional theory level, implemented in the Vienna ab initio simulation package (VASP, version 5.3.5), ${ }^{49-51}$ using the Perdew-Burke-Ernzerhof (PBE) functional. ${ }^{52}$ Projector-augmented wave (PAW) pseudopotentials were used to consider the inner electrons, whereas valence electronic states were expanded in plane waves with an energy cutoff of $500 \mathrm{eV} .^{53} \mathrm{In}$ order to reduce the self-interaction error, an effective Hubbard potential $\left(U_{\text {eff }}\right)$ of $4.5 \mathrm{eV}$ was added to the $\mathrm{Ce}(4 \mathrm{f})$ states. $^{54}$ Spin-polarized calculations were performed when required. van der Waals contributions were included by using the D3 dispersion correction method of Grimme et al. ${ }^{55}$ The criteria for electronic and geometry optimization convergence were set to $10^{-6} \mathrm{eV}$ and $0.015 \mathrm{eV} \AA^{-1}$, respectively. The lattice parameter of $\mathrm{CeO}_{2}$ was optimized with a dense $7 \times 7 \times 7 \Gamma$ centered $k$-point mesh and an energy cutoff of $700 \mathrm{eV}$, leading to the lattice parameter $a_{\text {calc }}=5.492 \AA$, which is in good agreement (1.5\% deviation) with the experimental value of $a_{\exp }$ $=5.411 \AA^{56}$ The investigated (111) surface was thereafter modeled as periodically repeated slabs using a $3 \times 3 \times 1 \Gamma$ centered $k$-point mesh. The slabs were separated by $15 \AA$ of vacuum space on top and consisting of $3 \times 3$ unit cells with three and six layers of $\mathrm{Ce}$ and $\mathrm{O}$ atoms, of which the upper two $\mathrm{Ce}$ and four O layers were allowed to relax. Chlorination of the surface was considered in the uppermost layer by replacement of $\mathrm{O}$ atoms with $\mathrm{Cl}$ atoms. The regular $\mathrm{O}$-terminated $\mathrm{CeO}_{2}(100)$ surface was modeled as a $2 \times 2$ supercell as described in the literature with the same $k$-point sampling and vacuum space as for the (111) surface. ${ }^{57}$ The climbing image nudged elastic band (CI-NEB) method and corresponding vibrational analysis were used to identify the transition states in the reaction network. ${ }^{58,59}$ The structures, labeled with the same names as described in this work, are freely accessible from the ioChem-BD database. ${ }^{60,61}$ The vibrational, rotational, and translational entropies of gas-phase molecules were calculated using Gaussian 03W (Version 6.1) ${ }^{62}$ employing DFT with PBE 

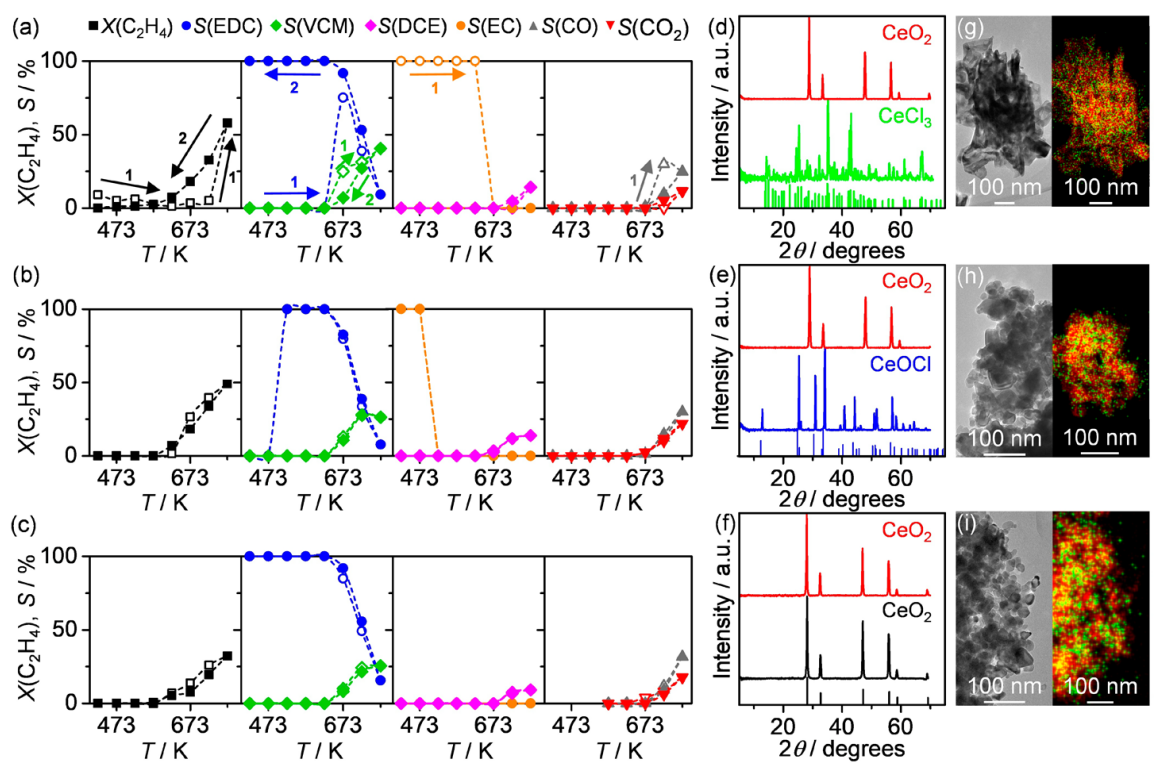

Figure 1. Ethylene conversion $(X)$ and selectivity $(S)$ versus temperature ramping up (arrow 1, open symbols) and down (arrow 2, solid symbols) over (a) $\mathrm{CeCl}_{3}-423$, (b) CeOCl-1023, and (c) $\mathrm{CeO}_{2}-1023$. Other conditions: $\mathrm{C}_{2} \mathrm{H}_{4}: \mathrm{HCl}_{2} \mathrm{O}_{2}=3: 4.8: 3, W_{\text {cat }}=0.5 \mathrm{~g}, F_{\text {tot }}=100 \mathrm{~cm}^{3} \mathrm{STP} \mathrm{min}^{-1}, P=1$ bar. XRD patterns of fresh (bottom) (d) $\mathrm{CeCl}_{3}-423$ (green), (e) $\mathrm{CeOCl}-1023$ (blue), and (f) $\mathrm{CeO}_{2}-1023$ (black) with corresponding reference patterns of $\mathrm{CeCl}_{3}$ (ICDD PDF 77-0154 and 01-0149), $\mathrm{CeOCl}$ (ICDD PDF 73-5027), and $\mathrm{CeO}_{2}$ (ICDD PDF 73-6318) and used catalysts (top, red) that all show only the $\mathrm{CeO}_{2}$ phase corresponding again to ICDD PDF 73-6318. (g-i) HRTEM images (left) and elemental maps (right, where red depicts $\mathrm{O}$ and green $\mathrm{Cl}$, respectively) of used catalysts corresponding to (a)-(c).

functionals, a cc-pVQZ basis set, the RMS force criterion set to $10^{-5}$, and the temperature set to $673.15 \mathrm{~K}$. The Gibbs free energy was calculated by taking the vibrational entropy into account, as implemented in Gaussian and described by Ochterski. $^{63}$

\section{RESULTS AND DISCUSSION}

3.1. Effect of Material Properties. In order to choose the right model catalyst for this study, the first step was to identify which type of material is present during the reaction by correlating steady-state activity with the bulk-phase composition. Figure $1 \mathrm{a}-\mathrm{c}$ depicts the conversion of ethylene and selectivity to various products in ethylene oxychlorination on $\mathrm{CeCl}_{3}, \mathrm{CeOCl}$, and $\mathrm{CeO}_{2}$. The temperature was cycled from 423 to $723 \mathrm{~K}$ and backward in order to achieve the strongest hysteresis behavior, as it can be expected that $\mathrm{CeCl}_{3}$ transforms to the oxide under an oxygen-containing atmosphere at high temperatures. The material that behaves quite differently from the rest during up- and downcycling is $\mathrm{CeCl}_{3}$, which shows first only formation of ethyl chloride before the conversion drops to almost zero until $723 \mathrm{~K}$, where about $58 \%$ conversion is reached. At this temperature, the product distribution is similar to that of $\mathrm{CeOCl}$ and $\mathrm{CeO}_{2}$, while the activity is about the same as that of $\mathrm{CeOCl}$ and a bit higher than that of $\mathrm{CeO}_{2}$. However, most importantly, the cooling part of the cycle is qualitatively the same in all three materials, suggesting a transformation of the different starting materials to one and the same phase. As $\mathrm{CeOCl}$ and $\mathrm{CeO}_{2}$ do not exhibit such a hysteresis behavior, it is likely that this common phase is an oxychloride, which either exists from the beginning in $\mathrm{CeOCl}$ or forms easily and quickly from $\mathrm{CeO}_{2}$ through chlorination already at low temperatures. $\mathrm{XRD}$ evidences the prevalence of bulk $\mathrm{CeO}_{2}$ in all samples after the test (Figure $1 \mathrm{~d}-\mathrm{f}$ ), whereas elemental mapping (Figure $1 \mathrm{~g}-\mathrm{i}$ ) shows the presence of oxygen and chlorine throughout all samples. Previous studies of $\mathrm{HCl}$ oxidation report that $\mathrm{CeO}_{2}$ mainly chlorinates on the surface or only to some extent in the near-subsurface region at $\mathrm{O}_{2}: \mathrm{HCl}$ feed ratios greater than $0.75,{ }^{32} 1,{ }^{37}$ or $2,{ }^{64}$ constituting a rather large spread.

As the ethylene oxychlorination reaction conditions used are in general closer to those reported in the first two publications, ceria was previously proven to be stable in oxychlorination of ethylene, ${ }^{27}$ and the XRD patterns of catalysts used in Figure $1 \mathrm{~d}-\mathrm{f}$ only show the presence of the oxide phase, we estimate that the bulk material keeps the oxide nature while the catalytically active surface consists of an oxychloride. In addition, key DFT calculations show that the energy required to displace one $\mathrm{Cl}$ atom from the surface to a subsurface position is $3 \mathrm{eV},{ }^{32}$ indicating that this is an unlikely event. The $\mathrm{CeOCl}$ and $\mathrm{CeO}_{2}$ samples used exhibit mostly octahedral morphologies, whereas the $\mathrm{CeO}_{2}$ formed from $\mathrm{CeCl}_{3}$ shows less developed crystals, likely due to insufficient oxygen availability during such a transformation. However, this insight into the composition of the surface does not yet allow conclusions about which facet of chlorinated ceria should be the model surface for further studies. Therefore, we investigated the performance of polycrystalline ceria and $\mathrm{CeO}_{2}$ nanocubes $\left(\mathrm{CeO}_{2}-873-\mathrm{E} 673\right.$ and $\mathrm{CeO}_{2}$-NC-E673), exposing predominantly the (111) and (100) surfaces, respectively. Figure S1 shows that there are no significant differences in selectivity between the nanocubic and polycrystalline samples when they are compared at equal conversion (Figure S2 depicts the relationship of conversion and product distribution of our standard sample). The only difference is the slightly decreased combustion in favor of higher selectivity to chlorinated hydrocarbons of $\mathrm{CeO}_{2}$-NC-E673, which can be explained by easier chlorination of the (100) surface in comparison to the (111) surface, evidenced by a much higher net (Table S1) and per surface area (Figure S1) chlorine uptake. The latter is likely also a reason for the reduced activity, together with the lower surface area of the nanocubes used (19 versus $\left.39 \mathrm{~m}^{2} \mathrm{~g}^{-1}\right)$. 

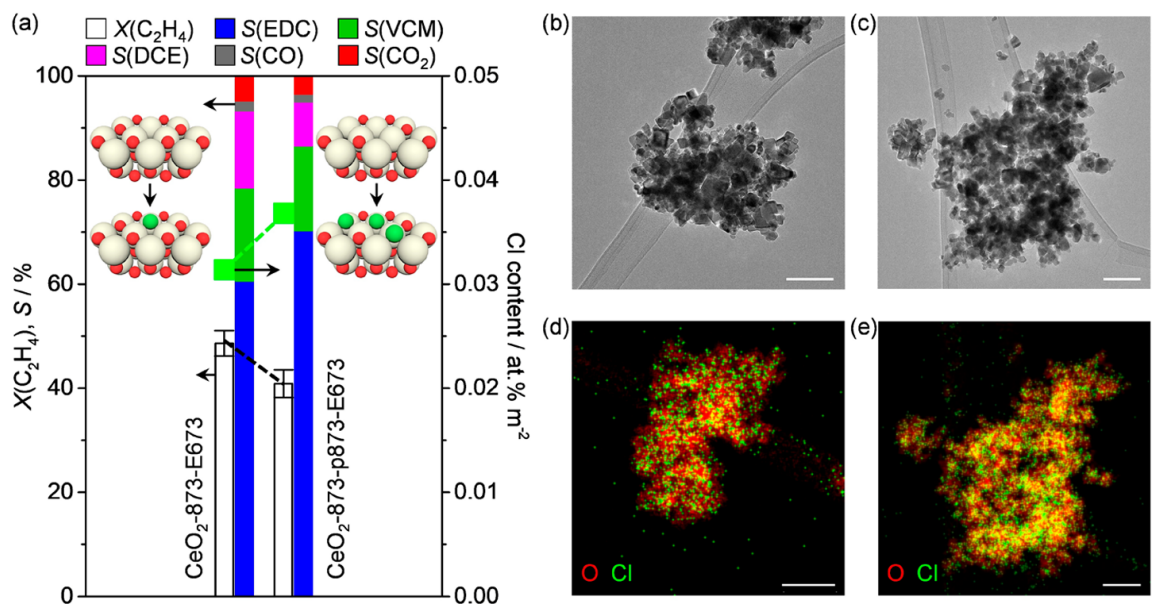

Figure 2. (a) Conversion and selectivity of ethylene oxychlorination at $673 \mathrm{~K}_{\text {on }} \mathrm{CeO}_{2}-873$ without pretreatment and with a prereduction in 5 vol \% $\mathrm{H}_{2}$ at $873 \mathrm{~K}$ for $2 \mathrm{~h}$. The right axis indicates the chlorine content per surface area of the used catalysts (see also Table S1). Other conditions:

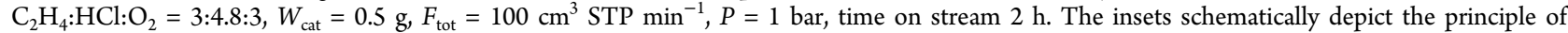
chlorination, where the top part shows $\mathrm{CeO}_{2}$ with a low or high amount of vacancies formed by prereduction, which leads to low or high chlorination (yellow Ce, red O, green $\mathrm{Cl}$ ). (b, c) HRTEM images and (d, e) elemental mapping of $\mathrm{CeO}_{2}-873-\mathrm{E} 673$ and $\mathrm{CeO}_{2}-873-\mathrm{p} 873-\mathrm{E} 673$. The scale bars in the micrographs represent $100 \mathrm{~nm}$.

Studies of $\mathrm{HCl}$ oxidation and trimethoxybenzene oxyhalogenation have previously shown similar results, where nanooctahedra exhibited a higher activity per surface area in comparison to nanocubes. ${ }^{64,65}$ However, the chlorine uptake was therein reported higher on the octahedra than on the cubes, in contrast with our findings, which is most likely linked to the different conditions and absence of ethylene. ${ }^{64}$ Furthermore, while the stabilities of the two different $\mathrm{CeO}_{2}$ morphologies under the reaction conditions are comparable, as evidenced by HRTEM analysis of fresh and used samples (Figure S1b-e), the (111) surface is generally more stable from a thermodynamic point of view. ${ }^{66}$

However, as the effect of oxygen vacancies and their possible chlorination is yet unclear, we conducted experiments with in situ prereduced $\mathrm{CeO}_{2}$, in order to create vacancies before exposing the material to our reaction conditions. These vacancies can be filled by oxygen or chlorine during the reaction, as depicted in the schemes in Figure 2a (see Table S1 for surface areas and chlorine contents), while chlorination is preferred by $0.89 \mathrm{eV}$ (vide infra). In turn, the higher degree of chlorination leads to less activity, less combustion, and improved EDC selectivity of $\mathrm{CeO}_{2}-873$-p873-E673 with respect to the reference sample $\mathrm{CeO}_{2}-873-\mathrm{E} 673$ (Figure 2a). Even though the structure is preserved in both cases (HRTEM images of used catalysts show no significant differences and octahedra are still clearly visible), elemental mapping also evidences much more chlorine in $\mathrm{CeO}_{2}$-873-p873-E673 than in $\mathrm{CeO}_{2}-873-\mathrm{E} 673$ (Figure $2 \mathrm{~b}-\mathrm{e}$ ), confirming the XRF measurements. Therefore, vacancies are at least partially healed by incorporation of chlorine rather than oxygen under the reaction conditions, thus creating a surface oxychloride structure and constituting an important factor determining the selectivity. The number of vacancies that form under reaction conditions was determined by measurement of the oxygen storage capacity (OSC), a technique widely applied in the literature. ${ }^{66}$

In general, an increase in the OSC of used materials in comparison to fresh $\mathrm{CeO}_{2}\left(50 \mu \mathrm{mol} \mathrm{O} \mathrm{O}^{-1}\right.$ for $\mathrm{CeO}_{2}-873-\mathrm{E} 673$ versus $34 \mu \mathrm{mol} \mathrm{O} \mathrm{g}^{-1}$ for $\left.\mathrm{CeO}_{2}-873\right)$ is observed. This increase in OSC would suggest that, during reaction, the surface or bulk of $\mathrm{CeO}_{2}$ is modified by the introduction of chlorine, which can then alter the way $\mathrm{CeO}_{2}$ interacts with $\mathrm{H}_{2} / \mathrm{O}_{2}$ during OSC measurements. Detection of chlorine traces by XRF (0.7 atom \%) in the sample even after four reduction/oxidation cycles indicates that chlorine modifies the material permanently. This is also evidenced by the OSC value, which stays constant at ca. $50 \mu \mathrm{mol} \mathrm{O} \mathrm{g}^{-1}$ after three cycles. The literature supports the presence of nonremovable chlorine in ceria, suggesting that $\mathrm{CeOCl}$ patches which form on the surface can grow into subsurface layers at temperatures at or above 673 $\mathrm{K}^{67,68}$ Furthermore, $\mathrm{Cl}$ was found to remain in the lattice until $1173 \mathrm{~K}$ under reducing conditions. ${ }^{69}$ Interestingly, prereduction of $\mathrm{CeO}_{2}$ with 5 vol $\% \mathrm{H}_{2}$ in $\mathrm{He}$ at $873 \mathrm{~K}$ has the same effect on the OSC as the oxychlorination reaction carried out at $673 \mathrm{~K}\left(\mathrm{CeO}_{2}-873-\mathrm{p} 873\right.$ and $\mathrm{CeO}_{2}-873-\mathrm{E} 673$ both exhibit an OSC of exactly $50 \mu \mathrm{mol} \mathrm{O} \mathrm{O}_{2} \mathrm{~g}^{-1}$ ). Furthermore, the prereduced sample after reaction $\mathrm{CeO}_{2}$-873-p873-E673 also exhibits an OSC of $53 \mu \mathrm{mol} \mathrm{O} \mathrm{g}^{-1}$. This corroborates the assumption that the incorporation of nonremovable chlorine in the bulk does facilitate vacancy formation in other areas of $\mathrm{CeO}_{2}$, as also observed in a study on chlorine poisoning of $\mathrm{Ce} / \mathrm{Zr}$ mixed oxide catalysts. ${ }^{70}$ However, further investigations of these aspects would go beyond the scope of this work. In conclusion, vacancies and chlorination are strongly linked and cannot be discussed separately. While the existence of vacancies seems important to allow a certain extent of surface chlorination which suppresses combustion and allows the reaction to take place, too many vacancies, leading to too high chlorination, are detrimental to the performance. Furthermore, even though it cannot be excluded that chlorine atoms from the surface diffuse into subsurface layers, substantial subsurface chlorine populations are unlikely, as they correspond to highly endothermic processes. Taking all of the above into account, a stoichiometric $\mathrm{CeO}_{2}(111)$ surface as reference and the same surface with one defect, i.e., one vacancy that can be filled by one chlorine atom, became the surfaces of choice for the DFT investigations.

3.2. Reaction Mechanism. Initial calculations of the two model surfaces showed the existence of three distinct adsorption sites, of which the stoichiometric surface exhibits 
two (lattice oxygen and lattice cerium atoms) and the defective surface exhibits an oxygen vacancy in addition. $\mathrm{HCl}$ adsorbs dissociatively on $\mathrm{CeO}_{2}(111)$, where the hydrogen proton binds to a lattice oxygen and the chlorine anion adsorbs either on top of a Ce atom $\left(E_{\mathrm{ads}}=-1.40 \mathrm{eV}\right)$ or in an oxygen vacancy $\left(E_{\mathrm{ads}}=\right.$ $-3.16 \mathrm{eV}$ ). As the difference in adsorption energy is relatively high, it is plausible that, once vacancies exist, chlorine will predominantly fill them, in accordance with high $\mathrm{Cl}$ activation barriers in $\mathrm{HCl}$ oxidation. ${ }^{32}$ In contrast to the (111) surface, $\mathrm{HCl}$ adsorption on the regular O-terminated (100) surface $^{57}$ is much stronger $\left(E_{\text {ads }}(\mathrm{HCl})=-3.64 \mathrm{eV}\right.$ and $E_{\text {ads }}(2 \mathrm{HCl})=-6.08$ $\mathrm{eV})$ and $\mathrm{Cl}$ evolution is very energy intensive $(2.64 \mathrm{eV})$ and thus unlikely. Therefore, once $\mathrm{HCl}$ adsorbs on $\mathrm{CeO}_{2}(100), \mathrm{Cl}$ is very likely to stay on that surface, thus poisoning it, which explains the relative inertness of this surface. Similar to $\mathrm{HCl}$ adsorption on $\mathrm{CeO}_{2}(111)$, even though nondissociative, chlorinated hydrocarbons also occupy up to three adsorption sites simultaneously. While ethylene adsorbs on top of a lattice cerium, chlorinated hydrocarbons occupy one lattice oxygen and neighboring $\mathrm{Ce}$ atoms or vacancies (Figures S3 and S4). The same holds for chemisorbed intermediates, where lattice oxygen creates a bond to one $\mathrm{C}$ atom and the potential chlorine ends orient so that they occupy $\mathrm{Ce}$ atoms or vacancies (vide infra). A comparison of the adsorption energies of ethylene and chlorinated products on a stoichiometric, an oxygen vacant, and a chlorinated surface (Figure 3 and Table S2) shows that

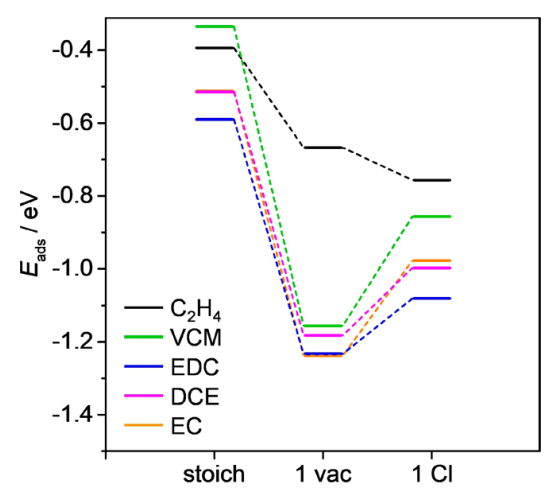

Figure 3. Adsorption energies of ethylene and chlorinated products on a stoichiometric surface (stoich) and two defect surfaces with either one oxygen vacancy $(1 \mathrm{vac})$ or one incorporated chlorine atom $(1 \mathrm{Cl})$.

ethylene is generally weakly adsorbed and EDC is always the most strongly adsorbed compound, with the exception of the case with one oxygen vacancy, where EC adsorbs with the same energy. DCE exhibits a slightly weaker adsorption, similar to the case for EC, while VCM is always the least strongly bound product. Therefore, EDC, EC, and DCE are more likely to take part in further transformations in comparison to VCM if the barriers are reasonably low. This is very desirable, however, VCM is only on the stoichiometric surface less strongly adsorbed than ethylene and the adsorption energies of all products on the oxygen vacant surface are very close. The latter can be explained by the fact that the presence of a vacancy acts as an ideal trapping site for the chlorinated end of each molecule and therefore other contributions are less important (Figure S4). Nevertheless, the result of this comparison is not in line with the experimentally observed selectivity (Figures 1 and 2 and Figure S2) and therefore not sufficient to unravel the mechanism of ethylene oxychlorination on $\mathrm{CeO}_{2}$.
Our previous work proposes a sequential mechanism of ethylene oxychlorination to EDC and its dehydrochlorination to VCM, as depicted in dashed black lines in Figure 4, which represents the starting point of a transition state investigation on a stoichiometric and defective surface. However, some elementary steps in this pathway are highly unlikely due to high barriers for the formation of EDC (stoichiometric $1.98 \mathrm{eV}$, defective $2.77 \mathrm{eV}$, step 3 in Table S2). In addition, step 14 rendered unfeasible, as the removal of one chlorine atom always also involves the stripping of the second chlorine atom, leading to a surface-bound $\mathrm{C}_{2} \mathrm{H}_{3}$. Therefore, this pathway needs to be discarded, but an alternative consecutive mechanism could be imagined by ceria enabling concerted steps, ${ }^{71}$ i.e., the combination of individual steps into one elementary step, as depicted by solid black arrows in Figure 4. Herein, path 1a combines the addition of one chlorine atom from a vacancy and another chlorine atom that is adsorbed on top of a cerium atom to ethylene. The following path $7 \mathrm{a}$ represents the simultaneous abstraction of $\mathrm{H}$ and $\mathrm{Cl}$ from EDC, directly leading to VCM. Figure 5 and Table 1 report the reaction profile along these paths.

In fact, step 1a was found to consist of two individual steps (reaction coordinates 2-6, steps 1a-1 and 1a-2) with barriers of 1.16 and $0.60 \mathrm{eV}$, as the chlorine addition is not fully symmetric and thus a non-surface-bound $\mathrm{C}_{2} \mathrm{H}_{4} \mathrm{Cl}$ intermediate with only real frequencies exists. In other words, after ethylene and $\mathrm{HCl}$ adsorption from the gas phase, ethylene attacks the chlorine on top of a cerium atom (reaction coordinates 2-4), while in the second part, this intermediate directly picks up the chlorine from a vacancy (left inset in Figure 5). Nevertheless, this path is still greatly favored over the two individual steps with a surfacebound $\mathrm{C}_{2} \mathrm{H}_{4} \mathrm{Cl}$ intermediate or the situation with two chlorinated vacancies $\left(E_{\mathrm{a}}>3 \mathrm{eV}\right)$. Therefore, it cannot be considered a single elementary step, most likely because it encompasses the rotation that creates the reacting intermediate. On the other hand, the third transition state at reaction coordinate 7 (right inset in Figure 5) involves a truly simultaneous stripping of one chlorine by a vacancy and one hydrogen by a lattice oxygen, resulting in a barrier of only 0.48 $\mathrm{eV}$. In contrast to the previous steps, this $\mathrm{H}-\mathrm{Cl}$ extrusion does not involve a rotation, allowing the creation of a largely stabilized six-membered ring, formed by the surface and the transition state structure. Plots of the charge density (insets in Figure 5) evidence this hypothesis. However, EDC is the dominating product in comparison to VCM as experimentally observed, which can be explained by the lower $\Delta G$ value for EDC desorption in comparison to the barrier for its transformation to VCM.

In mechanistic investigations through density functional theory, selectivity is retrieved by the comparison of the desired path against potential side routes leading to the same or secondary products. Such an alternative route to form VCM could be offered by dehydrogenation of $\mathrm{C}_{2} \mathrm{H}_{5} \mathrm{Cl}$ (EC) or its corresponding intermediate $\mathrm{C}_{2} \mathrm{H}_{4} \mathrm{Cl}$. However, while the latter is in principle possible with a barrier of $1.68 \mathrm{eV}$ (path 4 in Figures 4 and 6 and Table 2), EC formation itself is highly unlikely. While the stoichiometric surface prohibits EC formation completely, the defect surface allows at least a very easy transformation of a surface alcohol $\left(\mathrm{C}_{2} \mathrm{H}_{4} \mathrm{ClOH}\right)$ to EC $\left(E_{\mathrm{a}}=0.04 \mathrm{eV}\right)$. However, such a surface alcohol formation is strongly endothermic $\left(E_{\mathrm{r}}=1.5 \mathrm{eV}\right)$ and thus the formation of EC can be excluded (path 2, 2a, 5, 6, 8 in Figure 4 and Figure S13 and Tables S3 and S4). 


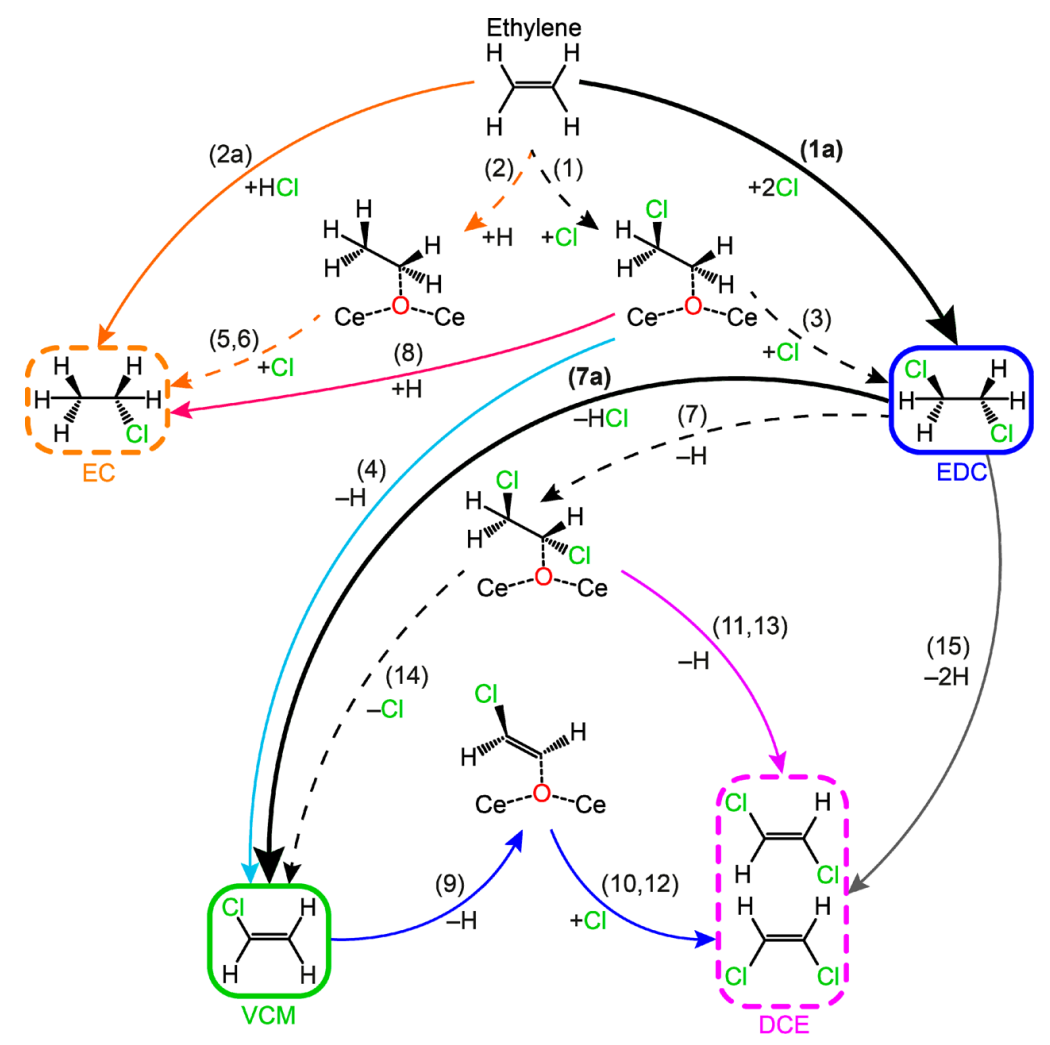

Figure 4. Schematic reaction network showing the main pathway (solid black) leading to EDC and VCM and side pathways leading either to VCM (light blue) or chlorinated side products (orange, magenta, purple, blue, gray). Solid (dashed) boxes indicate desired (undesired) products. For the sake of clarity, all truly reversible reactions are displayed in a single direction. The arrow labels indicate the transferred atom and the reaction number corresponding to Table S2 and Figures S5-S12. The main path leading to the desired product is highlighted by the black thick arrows. Dashed arrows represent pathways that were found to be highly unlikely. Surface-bound intermediates are depicted with a surface excerpt of two Ce and one $\mathrm{O}$ atom. The barrier of surface $\mathrm{Cl}$ diffusion (step 5) was $0.40 \mathrm{eV}$.

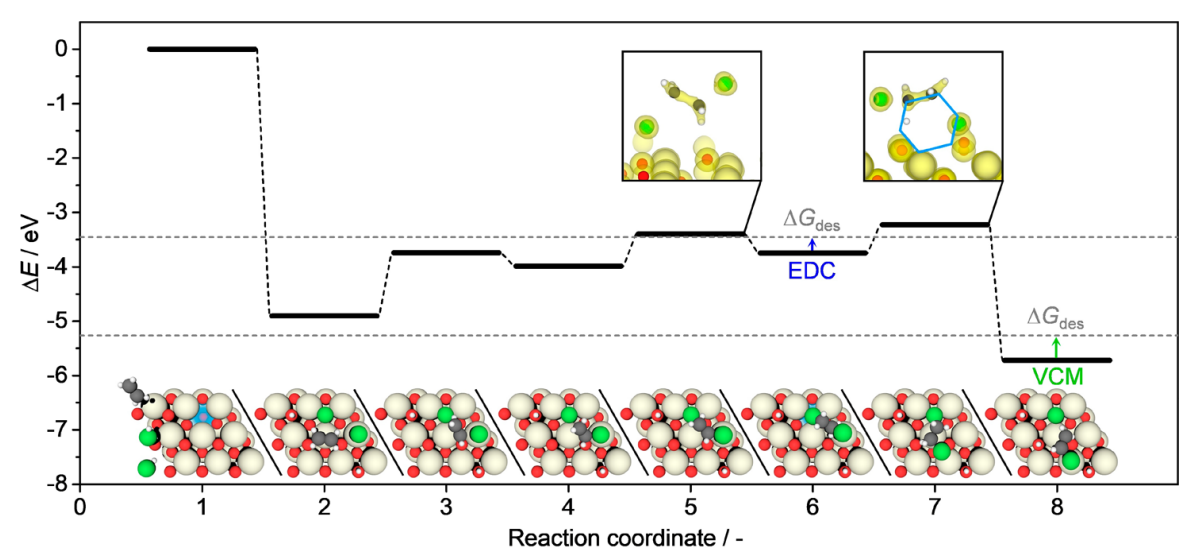

Figure 5. Reaction profile and corresponding optimized structures for ethylene oxychlorination and EDC dehydrochlorination on a defective $\mathrm{CeO}_{2}(111)$ surface (solid black pathway, i.e. steps 1a and 7a in Figure 4 and Table S2) including the Gibbs free energy difference for desorption. The reaction coordinates are described in Table 1 . The blue glow in the structures highlights a vacancy. The insets depict one individual (left) and a concerted (right) transition state. The yellow overlay represents the charge density (isosurface level $0.2309 \mathrm{le}^{-} \mid \AA^{-3}$ ). Color code: oxygen, red; cerium, yellow; carbon, black; chlorine, green; hydrogen, white.

Formation of the undesired byproducts cis- and trans-DCE is possible through steps 11 and 13 from the surface-bound intermediate $\mathrm{C}_{2} \mathrm{H}_{3} \mathrm{Cl}_{2}$ (Figure S14 and Table S5), favoring the cis isomer, which reflects the experimental observation. However, this mechanism is rather unlikely, as it only works on a stoichiometric surface or patches where no vacancy is near. Otherwise, the concerted step $7 \mathrm{a}$ would directly lead to VCM and the necessary surface intermediate would not exist. Furthermore, even on a stoichiometric surface, step 7a exhibits only a barrier of $0.61 \mathrm{eV}$, which is $0.56 \mathrm{eV}$ lower than the formation of the necessary intermediate (step 7), making this path even more unlikely. Both alternative pathways to yield DCE (blue and gray in Figure 4, steps 9, 10, 12, 15) with VCM or EDC as a starting point exhibit relatively high barriers. 
Table 1. Intermediates, State Descriptions, Energies with Respect to Gas-Phase Reactants $(\Delta E)$, Reaction Energies with Respect to the Previous Intermediate $\left(E_{\mathrm{r}}\right)$, Activation Energies $\left(E_{\mathrm{a}}\right)$, and Imaginary Frequencies of Transition States $\left(\nu_{\mathrm{i}}\right)$, Corresponding to Figure $5^{a}$

\begin{tabular}{|c|c|c|c|c|c|}
\hline intermediate & state description & $\Delta E(\mathrm{eV})$ & $E_{\mathrm{r}}(\mathrm{eV})$ & $E_{\mathrm{a}}(\mathrm{eV})$ & $\nu_{\mathrm{i}}\left(\mathrm{cm}^{-1}\right)$ \\
\hline 1 & $\mathrm{C}_{2} \mathrm{H}_{4}(\mathrm{~g})+2 \mathrm{HCl}(\mathrm{g})+\square+2^{*}+2 \square$ & 0 & & & \\
\hline 2 & $\mathrm{C}_{2} \mathrm{H}_{4}^{*}+\mathrm{Cl} \square+\mathrm{Cl}^{*}+2 \mathrm{H} \square$ & -4.90 & -4.90 & & \\
\hline 3 & $\mathrm{C}_{2} \mathrm{H}_{4}{ }_{-}-\mathrm{Cl} \square+\mathrm{Cl}^{*}+2 \mathrm{H} \square$ & -3.74 & & 1.16 & 254 \\
\hline 4 & $\mathrm{C}_{2} \mathrm{H}_{4} \mathrm{Cl}^{*} \square+\mathrm{Cl}^{*}+2 \mathrm{H} \square$ & -3.99 & 0.91 & & \\
\hline 5 & $\mathrm{C}_{2} \mathrm{H}_{4} \mathrm{Cl}^{*} \square--\mathrm{Cl}^{*}+2 \mathrm{H} \square$ & -3.39 & & 0.60 & 239 \\
\hline 6 & $\mathrm{C}_{2} \mathrm{H}_{4} \mathrm{Cl}_{2} * \square *+2 \mathrm{H} \square$ & -3.70 & 0.29 & & \\
\hline 7 & $\mathrm{C}_{2} \mathrm{H}_{3} \mathrm{Cl}^{*} *_{-}-\mathrm{Cl} \square--\mathrm{H} \square+2 \mathrm{H} \square$ & -3.22 & & 0.48 & 612 \\
\hline 8 & $\mathrm{C}_{2} \mathrm{H}_{3} \mathrm{Cl}^{* *}+\mathrm{Cl} \square+3 \mathrm{H} \square$ & -5.72 & -1.94 & & \\
\hline
\end{tabular}

${ }^{a}$ The symbol $\square$ denotes a lattice oxygen, $\square$ an oxygen vacancy, and * a lattice cerium, respectively. Multiple symbols indicate occupation of multiple sites by the adsorbate. In transition states, the added or stripped atom is indicated with a double dash (- -).

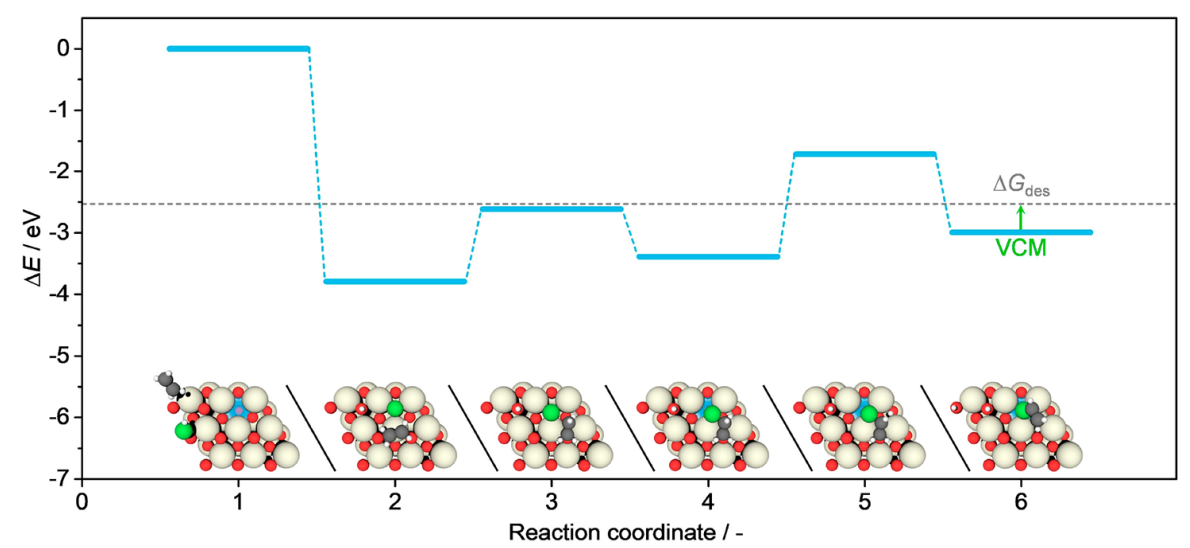

Figure 6. Reaction profile and corresponding optimized structures for direct VCM formation from ethylene on a defective $\mathrm{CeO}_{2}(111)$ surface (light blue pathway, i.e. steps 1 and 4 in Figure 4 and Table S2) including the Gibbs free energy difference for desorption. The reaction coordinates are described in Table 2. The blue glow in the structures highlights a vacancy. The color code is the same as in Figure 5.

Table 2. Intermediates, State Descriptions, Energies with Respect to Gas Phase Reactants $(\Delta E)$, Reaction Energies with Respect to the Previous Intermediate $\left(E_{\mathrm{r}}\right)$, Activation Energies $\left(E_{\mathrm{a}}\right)$, and Imaginary Frequencies of Transition States $\left(\nu_{\mathrm{i}}\right)$, corresponding to Figure $6^{a}$

\begin{tabular}{|c|c|c|c|c|c|}
\hline intermediate & state description & $\Delta E(\mathrm{eV})$ & $E_{\mathrm{r}}(\mathrm{eV})$ & $E_{\mathrm{a}}(\mathrm{eV})$ & $\nu_{\mathrm{i}}\left(\mathrm{cm}^{-1}\right)$ \\
\hline 1 & $\mathrm{C}_{2} \mathrm{H}_{4}(\mathrm{~g})+\mathrm{HCl}(\mathrm{g})+\square+*+2 \square$ & 0 & & & \\
\hline 2 & $\mathrm{C}_{2} \mathrm{H}_{4} *+\mathrm{Cl} \square+\mathrm{H} \square+\square$ & -3.79 & -3.79 & & \\
\hline 3 & $\mathrm{C}_{2} \mathrm{H}_{4} *-\mathrm{Cl} \square+\mathrm{H} \square+\square$ & -2.61 & & 1.18 & 278 \\
\hline 4 & $\mathrm{C}_{2} \mathrm{H}_{4} \mathrm{Cl} * \square+\mathrm{H} \square+\square$ & -3.38 & -0.40 & & \\
\hline 5 & $\mathrm{C}_{2} \mathrm{H}_{3} \mathrm{Cl} * \square--\mathrm{H} \square+\mathrm{H} \square$ & -1.71 & & 1.67 & 450 \\
\hline 6 & $\mathrm{C}_{2} \mathrm{H}_{3} \mathrm{Cl} * \square+2 \mathrm{H} \square$ & -2.99 & -0.39 & & \\
\hline
\end{tabular}

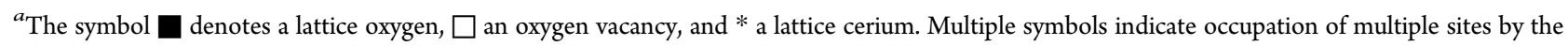
adsorbate. In transition states, the added or stripped atom is indicated with a double dash, - -

However, due to strong VCM and even stronger EDC adsorption on a vacancy, the blue and gray paths, both favoring the cis isomer, seem to represent the more likely mechanism of DCE formation (Figure 7 and Tables 3 and 4). Counterbalancing this process is only the fact that, even though VCM or EDC is strongly adsorbed on a vacancy, it can easily be displaced by $\mathrm{HCl}$ or $\mathrm{O}_{2}$ adsorption.

Oxidation processes were studied by investigating the energy barriers of chemisorption of ethylene and VCM on a molecular $\mathrm{O}_{2}$ in a vacancy, which were both very low $(0.88$ and $1.01 \mathrm{eV})$. However, the probability of such a setting existing is extremely low, as $\mathrm{O}_{2}$ would easily split up when another vacancy is present (barrier of $0.80 \mathrm{eV}$ ), refilling of two vacancies (surface and subsurface) is possible, ${ }^{32}$ and chemisorption of a (chlorinated) gas-phase hydrocarbon is not possible on a lattice oxygen on the $\mathrm{CeO}_{2}(111)$ surface. Furthermore, the adsorption energy of $\mathrm{HCl}$ is $0.89 \mathrm{eV}$ higher than that of $\mathrm{O}_{2}$, resulting in the preferential adsorption of $\mathrm{HCl}$. As $\mathrm{O}_{2}$ activation leaving active $\mathrm{O}$ atoms on the surface is unlikely, the lateral oxidation processes have not been investigated further.

3.3. Direct Chlorination and Gas-Phase Contributions. From previous studies, we know that $\mathrm{CeO}_{2}$ exhibits considerable $\mathrm{HCl}$ oxidation activity at conditions close to our reaction conditions, ${ }^{28,32}$ prompting an investigation of gasphase and direct chlorination contributions. As depicted in Figure $8 \mathrm{a}, \mathrm{b}$, direct chlorination, i.e., addition of $\mathrm{Cl}_{2}$ to ethylene, or formation of VCM through replacement of $\mathrm{H}$ by $\mathrm{Cl}$ reaches about $50 \%$ conversion over quartz particles and about $60 \%$ 


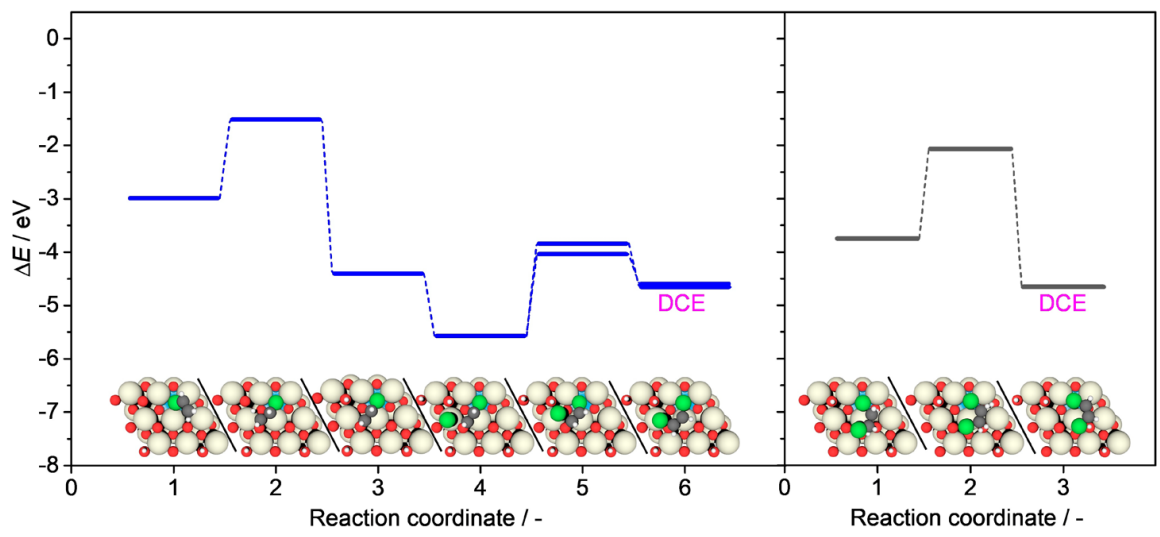

Figure 7. Reaction profile and corresponding optimized structures for DCE formation from VCM (end of step 4, Figure 6) on a defective $\mathrm{CeO}_{2}(111)$ surface through steps 9, 10, and 12 in Figure 4 and Table S2 (left), with the reaction coordinates described in Table 3. Reaction profile and corresponding optimized structures for DCE formation from EDC (end of step 1a-2, Figure 5) on a defective $\mathrm{CeO}_{2}(111)$ surface through step 15 (right), with the reaction coordinates described in Table 4. The color code is the same as in Figure 5.

Table 3. Intermediates, State Descriptions, Energies with Respect to Gas-Phase Reactants $(\Delta E)$, Reaction Energies with Respect to the Previous Intermediate $\left(E_{\mathrm{r}}\right)$, Activation Energies $\left(E_{\mathrm{a}}\right)$, and Imaginary Frequencies of Transition States $\left(\nu_{\mathrm{i}}\right)$, Corresponding to Figure $7^{a}$

\begin{tabular}{|c|c|c|c|c|c|}
\hline intermediate & state description & $\Delta E(\mathrm{eV})$ & $E_{\mathrm{r}}(\mathrm{eV})$ & $E_{\mathrm{a}}(\mathrm{eV})$ & $\nu_{\mathrm{i}}\left(\mathrm{cm}^{-1}\right)$ \\
\hline 1 & $\mathrm{C}_{2} \mathrm{H}_{3} \mathrm{Cl} * \square+2 \mathrm{H} \square+\square$ & -2.99 & & & \\
\hline 2 & $\mathrm{C}_{2} \mathrm{H}_{2} \mathrm{Cl} * \square-\mathrm{H} \square+2 \mathrm{H} \square$ & -1.51 & & 1.48 & 1499 \\
\hline 3 & $\mathrm{C}_{2} \mathrm{H}_{2} \mathrm{Cl}^{*} \square+3 \mathrm{H} \square+*+\square+\mathrm{HCl}(\mathrm{g})$ & -4.40 & -1.41 & & \\
\hline 4 & $\mathrm{C}_{2} \mathrm{H}_{2} \mathrm{Cl}^{*} \square+4 \mathrm{H} \square+\mathrm{Cl}^{*}$ & $-5.57 /-5.94$ & $-1.17 /-1.54$ & & \\
\hline 5 & $\mathrm{c} / \mathrm{t}-\mathrm{C}_{2} \mathrm{H}_{2} \mathrm{Cl} * \square--\mathrm{Cl}^{*}+4 \mathrm{H} \square$ & $-3.84 /-4.04$ & & $1.73 / 1.90$ & $376 / 365$ \\
\hline 6 & $\mathrm{c} / \mathrm{t}-\mathrm{C}_{2} \mathrm{H}_{2} \mathrm{Cl}_{2} * \square^{*}+4 \mathrm{H} \square$ & $-4.65 /-4.59$ & $0.92 / 1.35$ & & \\
\hline
\end{tabular}

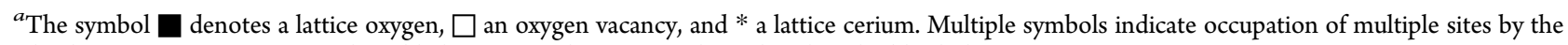
adsorbate. In transition states, the added or stripped atom is indicated with a double dash, - - .

Table 4. Intermediates, State Descriptions, Energies with Respect to Gas-Phase Reactants $(\Delta E)$, Reaction Energies with Respect to the Previous Intermediate $\left(E_{\mathrm{r}}\right)$, Activation Energies $\left(E_{\mathrm{a}}\right)$, and Imaginary Frequencies of Transition States $\left(\nu_{\mathrm{i}}\right)$, Corresponding to Figure $7^{a}$

\begin{tabular}{|c|c|c|c|c|c|}
\hline intermediate & state description & $\Delta E(\mathrm{eV})$ & $E_{\mathrm{r}}(\mathrm{eV})$ & $E_{\mathrm{a}}(\mathrm{eV})$ & $\nu_{\mathrm{i}}\left(\mathrm{cm}^{-1}\right)$ \\
\hline 1 & $\mathrm{C}_{2} \mathrm{H}_{4} \mathrm{Cl}_{2} * \square^{*}+2 \mathrm{H} \square+2 \square$ & -3.75 & & & \\
\hline 2 & $\mathrm{C}_{2} \mathrm{H}_{2} \mathrm{Cl}_{2} * \square^{*}-\mathrm{H} \square--\mathrm{H} \square+2 \mathrm{H} \square$ & -2.12 & & 1.63 & 601 \\
\hline 3 & $\mathrm{c}-\mathrm{C}_{2} \mathrm{H}_{2} \mathrm{Cl}_{2} * \square^{*}+4 \mathrm{H} \square$ & -4.65 & -0.90 & & \\
\hline
\end{tabular}

${ }^{a_{T}}$ The symbol $\square$ denotes a lattice oxygen, $\square$ an oxygen vacancy, and * a lattice cerium. Multiple symbols indicate occupation of multiple sites by the adsorbate. In transition states, the added or stripped atom is indicated with a double dash, - -

conversion over $\mathrm{CeO}_{2}-873$ at $673 \mathrm{~K}$. In both cases, VCM is the dominant product. In order to ensure that quartz particles were inert and did not catalyze the reaction, a pure gas-phase test was conducted in an empty reactor, yielding the exact same performance (Figure S15a). Considering that, under equivalent conditions, the degree of $\mathrm{HCl}$ conversion into $\mathrm{Cl}_{2}$ reaches 10 or $5 \%$ over $\mathrm{CeO}_{2}-873$ or $\mathrm{CeO}_{2}-\mathrm{NC}$ (Figure $8 \mathrm{c}$ and Figure S15b) - and comparing the oxychlorination activity (Figure $8 \mathrm{~d}$ ) it can be expected that at $673 \mathrm{~K}$ about $6-8 \%$ in total might stem from gas-phase direct chlorination. Figure 8e depicts the gas-phase activation energies of EDC and VCM formation from ethylene in which direct addition of $\mathrm{Cl}_{2}$ to ethylene to form EDC yields an energy barrier of $1.41 \mathrm{eV}$ while being exothermic by $-2.01 \mathrm{eV}$. In comparison to this direct addition, the literature also reports the possibility of radical-assisted mechanisms for direct halogenation, e.g., hydroxyl-assisted direct iodination of aromatics, highlighting the rich chemistry offered by halogenation reactions. ${ }^{72}$ The former barrier is only beaten by its lower counterpart $(1.32 \mathrm{eV})$ of direct VCM formation through a one-step dehydrogenation- $\mathrm{Cl}$ addition, where one hydrogen is stripped from ethylene by one $\mathrm{Cl}$ while the other $\mathrm{Cl}$ transfers to the $\mathrm{C}_{2} \mathrm{H}_{3}$ radical. The exothermicity of this reaction $(-1.31 \mathrm{eV})$ is however lower than for EDC formation, implying that EDC dehydrochlorination is endothermic by $0.70 \mathrm{eV}$. In addition, the latter presents a very high energy barrier of $2.47 \mathrm{eV}$, excluding the dehydrogenation pathway in the gas phase. Even EDC-, $\mathrm{HCl}$-, or $\mathrm{O}_{2}$-assisted dehydrochlorination, i.e., the presence of one of the above molecules in the close surroundings of EDC, did not significantly change the barrier. Prompted by this result, we conducted gas-phase dehydrochlorination of EDC with and without cofed $\mathrm{HCl}$ or $\mathrm{O}_{2}$, supporting the calculations, as no conversion could be observed until $723 \mathrm{~K}$ ( $6 \%$ only for cofed $\mathrm{HCl}$; no conversion otherwise, Figure S15c). Thus, reactions in the gas phase predominantly yield VCM, as direct VCM 

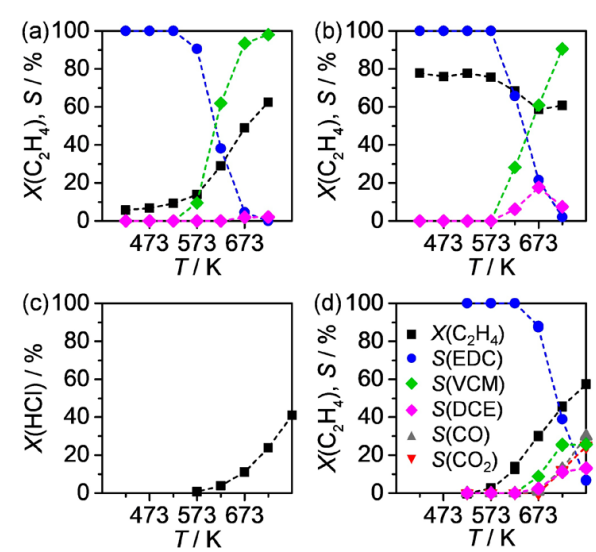

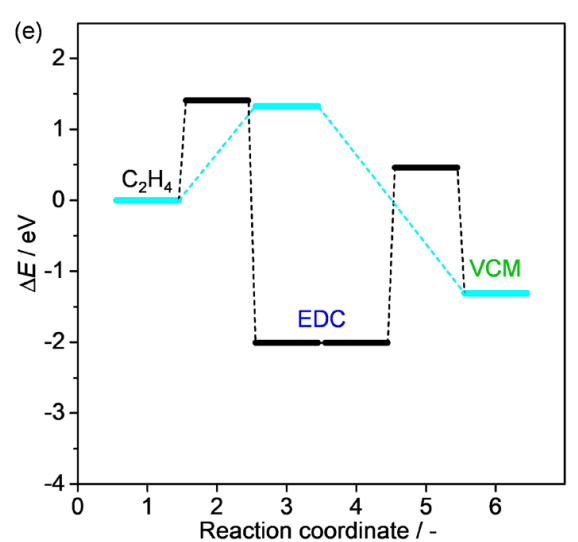

Figure 8. Conversion $(X)$ and selectivity $(S)$ versus temperature in steady-state catalytic tests of (a) direct chlorination with $\mathrm{C}_{2} \mathrm{H}_{4}: \mathrm{Cl}_{2}=3: 2.4$ on quartz and (b) $\mathrm{CeO}_{2}-873$, (c) $\mathrm{HCl}$ oxidation with $\mathrm{HCl}: \mathrm{O}_{2}=4.8: 3$ on $\mathrm{CeO}_{2}-873$, and (d) oxychlorination on $\mathrm{CeO}_{2}-873$ with $\mathrm{C}_{2} \mathrm{H}_{4}: \mathrm{HCl}_{2}: \mathrm{O}_{2}=3: 4.8: 3$. Other conditions: $W_{\text {cat }}=0.5 \mathrm{~g}, F_{\text {tot }}=100 \mathrm{~cm}^{3} \mathrm{STP} \mathrm{min}^{-1}, P=1$ bar. (e) Reaction profile for gas-phase ethylene chlorination and subsequent EDC dehydrochlorination (black) and gas-phase direct VCM formation from ethylene (light blue).
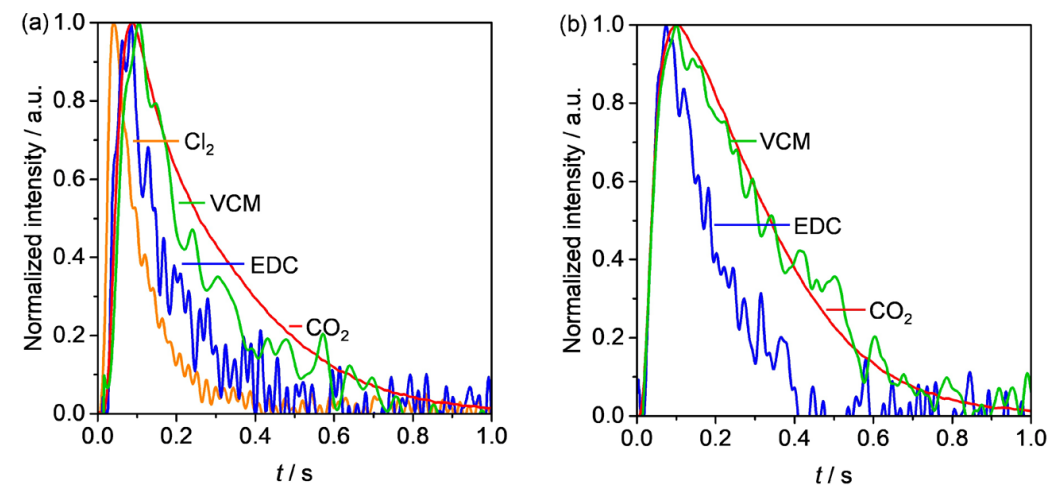

Figure 9. Normalized transient responses of (a) $\mathrm{Cl}_{2}, \mathrm{VCM}, \mathrm{EDC}$, and $\mathrm{CO}_{2}$ upon simultaneous pulsing of $\mathrm{HCl}: \mathrm{Ar}=1: 1$ and $\mathrm{C}_{2} \mathrm{H}_{4}: \mathrm{O}_{2}: \mathrm{Ne}=1: 1: 1$ at $773 \mathrm{~K}$ and (b) VCM, EDC, and $\mathrm{CO}_{2}$ upon simultaneous pulsing of $\mathrm{Cl}_{2}: \mathrm{Ar}=1: 1$ and $\mathrm{C}_{2} \mathrm{H}_{4}: \mathrm{O}_{2}: \mathrm{Ne}=1: 1: 1$ at $773 \mathrm{~K}$.

formation is favored over EDC formation, while EDC dehydrochlorination is nonexistent.

3.4. Temporal Analysis of Products. In an attempt to corroborate the theoretical reaction scheme described above, we conducted transient experiments with submillisecond time resolution on pre-equilibrated $\mathrm{CeO}_{2}-873-\mathrm{E} 673$. Figure 9a depicts the height-normalized transient responses of $\mathrm{Cl}_{2}$, EDC, VCM, and $\mathrm{CO}_{2}$, recorded after simultaneous pulsing of $\mathrm{HCl}, \mathrm{C}_{2} \mathrm{H}_{4}$, and $\mathrm{O}_{2}$. Herein, $\mathrm{Cl}_{2}$ was the first product detected at the reactor outlet followed by EDC, VCM, and finally $\mathrm{CO}_{2}$. The same product formation sequence was observed in the absence of gas-phase $\mathrm{O}_{2}$ (i.e., when only $\mathrm{HCl}$ and $\mathrm{C}_{2} \mathrm{H}_{4}$ were simultaneously pulsed) (Figure S16). Notably, neither radicals nor EC was observed in these experiments, in agreement with the results of steady-state experiments and DFT. Therefore, the pink (8) and orange pathways $(2$ and 5,6$)$ of EC formation and its dehydrogenation to VCM in Figure 4 do not contribute to the overall reactivity. However, this does not necessarily exclude the second step of dehydrogenation (path 4 in Figure 4), which could still be part of the direct VCM formation from ethylene, even though it is not favored. Insight into this circumstance was indirectly derived from analyzing the order of appearance of EDC and VCM (Figure 9a), which suggests that $\mathrm{C}_{2} \mathrm{H}_{4}$ is initially converted into EDC followed by dehydrochlorination of the latter to VCM. This experimental finding supports the pathways predicted by DFT (i.e. $\mathrm{C}_{2} \mathrm{H}_{4} \rightarrow \mathrm{EDC} \rightarrow$
VCM, black arrows in Figure 4). As the same sequence of product formation was also observed in the absence of gasphase $\mathrm{O}_{2}$ (Figure S16), the above statement should be valid for a broad range of coverage by oxygen and chlorine species, thus supporting the validity of our chosen defect model surface. In addition, this experiment also revealed a correlation between the amount of formed chlorine-containing products (EDC and $\mathrm{VCM}$ ) and the amount of detected $\mathrm{Cl}_{2}$ (Figure S17), suggesting that high chlorine coverage favors both the formation of EDC/VCM and desorption of $\mathrm{Cl}_{2}$. This statement is in line with the hypothesis that both processes take place in parallel and increased temperature, and thus less poisoning through faster $\mathrm{Cl}_{2}$ evolution, leads to an increased yield of EDC and VCM.

In order to check if the source of chlorine, i.e. $\mathrm{HCl}$ or $\mathrm{Cl}_{2}$, influences the pathways of EDC and VCM formation, we performed experiments with simultaneous pulsing of $\mathrm{Cl}_{2}, \mathrm{C}_{2} \mathrm{H}_{4}$, and $\mathrm{O}_{2}$. Figure $9 \mathrm{~b}$ depicts the obtained height-normalized transient responses of EDC, VCM, and $\mathrm{CO}_{2}$. The order of appearance of these products indicates that EDC is the first chlorinated hydrocarbon formed from ethylene, which is in agreement with tests using $\mathrm{HCl}$ as chlorine source. Therefore, the order of the reaction steps including chlorination of $\mathrm{C}_{2} \mathrm{H}_{4}$ to EDC and subsequent dehydrochlorination of this product to VCM does not depend on the source of chlorine. This statement is in line with the observation in our calculations that 
both $\mathrm{HCl}$ and $\mathrm{Cl}_{2}$ immediately dissociate upon adsorption, regardless of vacancies being present or not.

In addition, the catalytic ability to dehydrochlorinate EDC was tested in separate experiments, resulting in the transient responses of EDC, VCM, CO, and $\mathrm{CO}_{2}$ as shown in Figure 10. The first observed product was VCM, further supporting the conclusion about an intermediate role of EDC upon conversion of $\mathrm{HCl}$ and $\mathrm{C}_{2} \mathrm{H}_{4}$ to VCM.

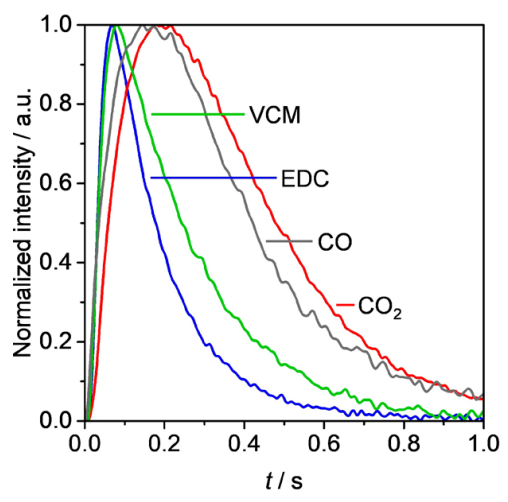

Figure 10. Normalized transient responses of VCM, EDC, CO, and $\mathrm{CO}_{2}$ upon pulsing of EDC:Ar $=1: 6$ at $773 \mathrm{~K}$.

Even though combustion products $\left(\mathrm{CO}\right.$ and $\left.\mathrm{CO}_{2}\right)$ account for the smallest fraction of products, they are yet substantial and an understanding of their formation is important for improving the catalyst performance. $\mathrm{CO}$ was not detected when $\mathrm{C}_{2} \mathrm{H}_{4}$ and $\mathrm{O}_{2}$ were simultaneously pulsed with $\mathrm{HCl}$ or $\mathrm{Cl}_{2}$ (Figure 9). This is also valid for the ethylene oxidation reaction in the absence of Cl-contacting reactants (Figure S18). Although it cannot be completely excluded that $\mathrm{CO}$ was formed in tiny amounts, which are below the detection limit, the main unselective pathway of $\mathrm{C}_{2} \mathrm{H}_{4}$ conversion is its oxidation to $\mathrm{CO}_{2}$. $\mathrm{CO}$ and $\mathrm{CO}_{2}$ were observed when EDC reacted with the catalyst in the absence of gas-phase $\mathrm{O}_{2}$. It is also possible that these carbon oxides originated from VCM. Thus, both ethylene and its chlorinated products are responsible for the formation of $\mathrm{CO}_{x}$ in the course of ethylene oxychlorination. In addition, lattice oxygen species appear to actively participate in these undesired processes.

\section{CONCLUSIONS}

The combination of computational analysis by the application of density functional theory with steady-state experiments and investigation of transient kinetics by temporal analysis of products revealed the mechanism of ethylene oxychlorination on $\mathrm{CeO}_{2}$. Experimental results suggest that the catalytic material consists of an oxide, supporting a surface oxychloride during reaction conditions. In addition, surface alterations by formation and chlorination of vacancies are an important factor determining the selectivity. While empty vacancies decrease the selectivity to EDC or VCM, facilitating their further transformation to DCE, chlorinated vacancies enable the formation of EDC in the first place, as evidenced by an increase of selectivity to desired products with higher surface chlorination. Different facets of ceria $((111)$ and $(100))$ did not show significant performance differences except for lower activity of the polar (100) surface, which was related to lower overall surface area and higher chlorination (poisoning) of the sample. Thus, the most stable (111) surface of $\mathrm{CeO}_{2}$ with one vacancy was chosen as a model catalyst. We revealed that the formation of VCM most likely proceeds through dehydrochlorination of EDC which is greatly facilitated on the defect surface, while pure dehydrogenation pathways that require $\mathrm{C}_{2} \mathrm{H}_{5} \mathrm{Cl}$ as an intermediate could be excluded. The major finding, enabling easy EDC to VCM transformation and thus making the proposed pathway feasible, is the ability of ceria to perform concerted elementary steps. Most importantly, of the three types of theoretical concerted steps, $\mathrm{HCl}, \mathrm{H}_{2}$, or $\mathrm{Cl}_{2}$ addition or abstraction, only $\mathrm{HCl}$ abstraction was found dominating and responsible for the excellent dehydrochlorination behavior of ceria, while $\mathrm{H}_{2}$ abstraction is feasible. The cause for this easy concerted $\mathrm{HCl}$ abstraction can be found in the formation of a hexagonal structure that is formed by the electron densities of the involved $\mathrm{C}, \mathrm{Cl}, \mathrm{H}, \mathrm{O}$, and $\mathrm{Ce}$ atoms. Furthermore, formation of other polychlorinated byproducts such as DCE is possible from either EDC or VCM, with concerted $\mathrm{H}$ abstraction, or through individual steps from VCM, given that EDC or VCM is adsorbed on a vacancy. In other words, chlorinated vacancies facilitate the formation of EDC and its dehydrochlorination to VCM, staying chlorinated at the end of the process. However, VCM that is formed through an alternative, yet less important, direct path without EDC as intermediate leads to a non-chlorine-filled vacancy, acting as an anchoring site and increasing its adsorption, which then enables DCE formation. Given that the cis isomer is the only experimentally observed product, and EDC also occupies a vacancy after its formation, EDC appears to be more likely to transform to DCE in comparison to VCM. These observations are supported by transient kinetic studies that evidenced the oxychlorination-dehydrochlorination pathway by revealing that EDC is always formed as the first product, regardless of the chlorine source, followed by VCM. In addition, separate EDC dehydrogenation experiments substantiated this path, while the absence of ethyl chloride intermediates excluded pure dehydrogenation processes for VCM formation. Furthermore, we revealed that $\mathrm{CO}$ mostly stems from the combustion of chlorinated hydrocarbons, whereas ethylene yields only $\mathrm{CO}_{2}$. Gas-phase chlorination, mostly yielding VCM, was found to be non-negligible, yet not governing, while EDC dehydrogenation is impossible in the gas phase.

The synergies obtained by the extensive combination of computational, steady state, and transient kinetic analysis in this study allow us to shed light on a complex reaction network of an industrially highly relevant reaction on $\mathrm{CeO}_{2}$, providing a basis for further development and simulation of oxide- or oxychloride-based catalysts for oxychlorination reactions.

\section{ASSOCIATED CONTENT}

S Supporting Information

Scheme of oxychlorination setup, additional characterization and catalytic data, optimized geometries of adsorbed species, and initial, transition state, and final geometries of elemental steps, additional reaction profiles, and additional TAP data (PDF)

\section{AUTHOR INFORMATION}

\section{Corresponding Authors}

*E-mail for N.L.: nlopez@iciq.es.

*E-mail for J.P.-R.: jpr@chem.ethz.ch. 


\section{ORCID $\odot$}

Marçal Capdevila-Cortada: 0000-0003-4391-6580

Alessandro Trovarelli: 0000-0002-1396-4031

Núria López: 0000-0001-9150-5941

Javier Pérez-Ramírez: 0000-0002-5805-7355

Notes

The authors declare no competing financial interest.

\section{ACKNOWLEDGMENTS}

This work was sponsored by Swiss National Science Foundation (project no. 200021-156107). The authors acknowledge Evgeniya Vorobjeva for HRTEM microscopy.

\section{REFERENCES}

(1) Businesswire. Global Polyvinyl Chloride (PVC) Market Worth USD 72.330 Billion by $2021 \mathrm{http} / / /$ www.businesswire.com/news/ home/20161115006496/en/Global-Polyvinyl-Chloride-PVC-MarketWorth-USD (accessed Sep 24, 2017).

(2) Johnston, P.; Carthey, N.; Hutchings, G. J. Discovery, development, and commercialization of gold catalysts for acetylene hydrochlorination. J. Am. Chem. Soc. 2015, 137, 14548-14557.

(3) Malta, G.; Kondrat, S. A.; Freakley, S. J.; Davies, C. J.; Lu, L.; Dawson, S.; Thetford, A.; Gibson, E. K.; Morgan, D. J.; Jones, W.; Wells, P. P.; Johnston, P.; Catlow, C. R. A.; Kiely, C. J.; Hutchings, G. $\mathrm{J}$. Identification of single-site gold catalysis in acetylene hydrochlorination. Science 2017, 355, 1399-1403.

(4) Oliver-Meseguer, J.; Doménech-Carbó, A.; Boronat, M.; LeyvaPérez, A.; Corma, A. Partial reduction and selective transfer of hydrogen chloride on catalytic gold nanoparticles. Angew. Chem., Int. Ed. 2017, 56, 6435-6439.

(5) Weissermel, K.; Arpe, H.-J. In Industrial Organic Chemistry 4; Wiley-VCH: Weinheim, Germany, 2008; pp 217-238.

(6) Naworski, J. S.; Velez, E. S. In Applied Industrial Catalysis 1; Academic Press: New York, 1983; pp 239-273.

(7) Pérez-Ramírez, J.; Mondelli, C.; Schmidt, T.; Schlüter, O. F.-K.; Wolf, A.; Mleczko, L.; Dreier, T. Sustainable chlorine recycling via catalysed $\mathrm{HCl}$ oxidation: from fundamentals to implementation. Energy Environ. Sci. 2011, 4, 4786-4799.

(8) Malentacchi, M.; Rubini, C. Oxychlorination catalytic composition for controlling exothermic reactions in a fixed bed. EP 1020222 B1, 2004.

(9) Muddada, N. B.; Fuglerud, T.; Lamberti, C.; Olsbye, U. Tuning the activity and selectivity of $\mathrm{CuCl}_{2} / \gamma-\mathrm{Al}_{2} \mathrm{O}_{3}$ ethene oxychlorination catalyst by selective promotion. Top. Catal. 2014, 57, 741-756.

(10) Muddada, N. B.; Olsbye, U.; Caccialupi, L.; Cavani, F.; Leofanti, G.; Gianolio, D.; Bordiga, S.; Lamberti, C. Influence of additives in defining the active phase of the ethylene oxychlorination catalyst. Phys. Chem. Chem. Phys. 2010, 12, 5605-5618.

(11) Henley, J. P.; Jones, M. E.; Hickman, D. A.; Marshall, K. A.; Reed, D. J.; Clarke, W. D.; Olken, M. M.; Walko, L. E. Process for vinyl chloride manufacture from ethane and ethylene with partial $\mathrm{HCl}$ recovery from reactor effluent. US $6933417 \mathrm{~B} 1,2005$.

(12) Van Rooijen, F. E.; Johan, J.; De Bruijn, A. Catalytic oxychlorination. US $0054708 \mathrm{Al}, 2009$.

(13) Loos, M.; Goulon, J.; Bertucci, M.; Bachelard, R. Structural studies using X.A.S. of the active species catalysing the oxychlorination of ethylene - II. Phys. B 1989, 158, 188-190.

(14) Lamberti, C.; Prestipino, C.; Bonino, F.; Capello, L.; Bordiga, S.; Spoto, G.; Zecchina, A.; Diaz Moreno, S.; Cremaschi, B.; Garilli, M.; Marsella, A.; Carmello, D.; Vidotto, S.; Leofanti, G. The chemistry of the oxychlorination catalyst: an in-situ, time-resolved XANES study. Angew. Chem., Int. Ed. 2002, 41, 2341-2344.

(15) Carmello, D.; Finocchio, E.; Marsella, A.; Cremaschi, B.; Leofanti, G.; Padovan, M.; Busca, G. An FT-IR and reactor study of the dehydrochlorination activity of $\mathrm{CuCl}_{2} / \gamma-\mathrm{Al}_{2} \mathrm{O}_{3}$-based oxychlorination catalysts. J. Catal. 2000, 191, 354-363.
(16) Leofanti, G. Alumina-supported copper chloride 3. Effect of exposure to ethylene. J. Catal. 2001, 202, 279-295.

(17) Muddada, N. B.; Olsbye, U.; Fuglerud, T.; Vidotto, S.; Marsella, A.; Bordiga, S.; Gianolio, D.; Leofanti, G.; Lamberti, C. The role of chlorine and additives on the density and strength of Lewis and Brønsted acidic sites of $\gamma-\mathrm{Al}_{2} \mathrm{O}_{3}$ support used in oxychlorination catalysis: A FTIR study. J. Catal. 2011, 284, 236-246.

(18) Carrubba, R. V.; Spencer, J. L. Kinetics of the oxychlorination of ethylene. Ind. Eng. Chem. Process Des. Dev. 1970, 9, 414-419.

(19) Gelperin, E. I.; Bakshi, Y. M.; Zyskin, A. G.; Snagovsky, Y. S.; Avetisov, A. K. Kinetics and mechanism of ethylene oxychlorination. Russ. Chem. Ind. 1996, 28, 356-363.

(20) Gianolio, D.; Muddada, N. B.; Olsbye, U.; Lamberti, C. Doped$\mathrm{CuCl}_{2} / \mathrm{Al}_{2} \mathrm{O}_{3}$ catalysts for ethylene oxychlorination: Influence of additives on the nature of active phase and reducibility. Nucl. Instrum. Methods Phys. Res., Sect. B 2012, 284, 53-57.

(21) Leofanti, G.; Marsella, A.; Cremaschi, B.; Garilli, M.; Zecchina, A.; Spoto, G.; Bordiga, S.; Fisicaro, P.; Berlier, G.; Prestipino, C.; Casali, G.; Lamberti, C. Alumina-supported copper chloride 4. Effect of exposure to $\mathrm{O}_{2}$ and HCl. J. Catal. 2001, 202, 279-295.

(22) Muddada, N. B.; Olsbye, U.; Leofanti, G.; Gianolio, D.; Bonino, F.; Bordiga, S.; Fuglerud, T.; Vidotto, S.; Marsella, A.; Lamberti, C. Quantification of copper phases, their reducibility and dispersion in doped-CuCl$/ \mathrm{Al}_{2} \mathrm{O}_{3}$ catalysts for ethylene oxychlorination. Dalt. Trans. 2010, 39, 8437-8449.

(23) Magistro, A. J.; Cowfer, J. A. Oxychlorination of ethylene. J. Chem. Educ. 1986, 63, 1056-1058.

(24) Wachi, S.; Asai, Y. Kinetics of 1,2-dichloroethane formation from ethylene and cupric chloride. Ind. Eng. Chem. Res. 1994, 33, 259264.

(25) Kurta, S. A. Investigating active centers of industrial catalysts for the oxidative chlorination of ethylene on a $\gamma-\mathrm{Al}_{2} \mathrm{O}_{3}$ surface. Catal. Ind. 2011, 3, 136-143.

(26) Kurta, S. A. Catalysis of ethylene oxychlorination into 1,2dichlorethane in the presence of $\mathrm{CuCl}_{2} / \mathrm{CuCl}$ active centers on the surface of $\gamma-\mathrm{Al}_{2} \mathrm{O}_{3}$. Chem. Chem. Technol. 2012, 6, 1-8.

(27) Scharfe, M.; Lira-Parada, P. A.; Paunovic, V.; Moser, M.; Amrute, A. P.; Pérez-Ramírez, J. Oxychlorination-dehydrochlorination chemistry on bifunctional ceria catalysts for intensified vinyl chloride production. Angew. Chem., Int. Ed. 2016, 55, 3068-3072.

(28) Scharfe, M.; Lira-Parada, P. A.; Amrute, A. P.; Mitchell, S.; Pérez-Ramírez, J. Lanthanide compounds as catalysts for the one-step synthesis of vinyl chloride from ethylene. J. Catal. 2016, 344, 524-534.

(29) Higham, M. D.; Scharfe, M.; Capdevila-Cortada, M.; PérezRamírez, J.; López, N. Mechanism of ethylene oxychlorination over ruthenium oxide. J. Catal. 2017, 353, 171-180.

(30) Montini, T.; Melchionna, M.; Monai, M.; Fornasiero, P. Fundamentals and catalytic applications of $\mathrm{CeO}_{2}$-based materials. Chem. Rev. 2016, 116, 5987-6041.

(31) Paier, J.; Penschke, C.; Sauer, J. Oxygen defects and surface chemistry of ceria: quantum chemical studies compared to experiment. Chem. Rev. 2013, 113, 3949-3985.

(32) Amrute, A. P.; Mondelli, C.; Moser, M.; Novell-Leruth, G.; López, N.; Rosenthal, D.; Farra, R.; Schuster, M. E.; Teschner, D.; Schmidt, T.; Pérez-Ramírez, J. Performance, structure, and mechanism of $\mathrm{CeO}_{2}$ in $\mathrm{HCl}$ oxidation to $\mathrm{Cl}_{2}$. J. Catal. 2012, 286, 287-297.

(33) Capdevila-Cortada, M.; Łodziana, Z.; López, N. Performance of $\mathrm{DFT}+\mathrm{U}$ approaches in the study of catalytic materials. ACS Catal. 2016, 6, 8370-8379.

(34) Loschen, C.; Carrasco, J.; Neyman, K. M.; Illas, F. Firstprinciples $\mathrm{LDA}+\mathrm{U}$ and GGA+U study of cerium oxides: Dependence on the effective U parameter. Phys. Rev. B: Condens. Matter Mater. Phys. 2007, 75, 35115.

(35) García-Melchor, M.; López, N. Homolytic products from heterolytic paths in $\mathrm{H}_{2}$ dissociation on metal oxides: The example of $\mathrm{CeO}_{2}$. J. Phys. Chem. C 2014, 118, 10921-10926.

(36) Carrasco, J.; Vilé, G.; Fernández-Torre, D.; Pérez, R.; PérezRamírez, J.; Ganduglia-Pirovano, M. V. Molecular-level understanding 
of $\mathrm{CeO}_{2}$ as a catalyst for partial alkyne hydrogenation. J. Phys. Chem. C 2014, 118, 5352-5360.

(37) Farra, R.; Eichelbaum, M.; Schlögl, R.; Szentmiklósi, L.; Schmidt, T.; Amrute, A. P.; Mondelli, C.; Pérez-Ramírez, J.; Teschner, D. Do observations on surface coverage-reactivity correlations always describe the true catalytic process? A case study on ceria. J. Catal. 2013, 297, 119-127.

(38) López, N.; Gómez-Segura, J.; Marín, R. P.; Pérez-Ramírez, J. Mechanism of $\mathrm{HCl}$ oxidation (Deacon process) over $\mathrm{RuO}_{2}$. J. Catal. 2008, 255, 29-39.

(39) Over, $\mathrm{H}$. Atomic-scale understanding of the $\mathrm{HCl}$ oxidation over $\mathrm{RuO}_{2}$, a novel deacon process. J. Phys. Chem. C 2012, 116, 6779-6792.

(40) Moser, M.; Paunovic, V.; Guo, Z.; Szentmiklósi, L.; Hevia, M. G.; Higham, M.; López, N.; Teschner, D.; Pérez-Ramírez, J. Interplay between surface chemistry and performance of rutile-type catalysts for halogen production. Chem. Sci. 2016, 7, 2996-3005.

(41) Farra, R.; Girgsdies, F.; Frandsen, W.; Hashagen, M.; Schlögl, R. Teschner, D. Synthesis and catalytic performance of $\mathrm{CeOCl}$ in Deacon reaction. Catal. Lett. 2013, 143, 1012-1017.

(42) Wu, Q.; Zhang, F.; Xiao, P.; Tao, H.; Wang, X.; Hu, Z.; Lü, Y. Great influence of anions for controllable synthesis of $\mathrm{CeO}_{2}$ nanostructures: from nanorods to nanocubes. J. Phys. Chem. C 2008, 112, 17076-17080.

(43) Wu, Z.; Li, M.; Howe, J.; Meyer, H. M.; Overbury, S. H. Probing defect sites on $\mathrm{CeO}_{2}$ nanocrystals with well-defined surface planes by Raman spectroscopy and $\mathrm{O}_{2}$ adsorption. Langmuir 2010, 26, 1659516606.

(44) Aneggi, E.; Wiater, D.; de Leitenburg, C.; Llorca, J.; Trovarelli, A. Shape-dependent activity of ceria in soot combustion. ACS Catal. 2014, 4, 172-181.

(45) Brunauer, S.; Emmett, P. H.; Teller, E. Adsorption of gases in multimolecular layers. J. Am. Chem. Soc. 1938, 60, 309-319.

(46) Pérez-Ramírez, J.; Kondratenko, E. V. Evolution, achievements, and perspectives of the TAP technique. Catal. Today 2007, 121, 160169.

(47) Gleaves, J. T.; Yablonsky, G.; Zheng, X.; Fushimi, R.; Mills, P. L. Temporal analysis of products (TAP) - Recent advances in technology for kinetic analysis of multi-component catalysts. J. Mol. Catal. A: Chem. 2010, 315, 108-134.

(48) Morgan, K.; Maguire, N.; Fushimi, R.; Gleaves, J. T.; Goguet, A.; Harold, M. P.; Kondratenko, E. V.; Menon, U.; Schuurman, Y.; Yablonsky, G. S. Forty years of temporal analysis of products. Catal. Sci. Technol. 2017, 7, 2416-2439.

(49) Kresse, G.; Hafner, J. Ab initio molecular dynamics for liquid metals. Phys. Rev. B: Condens. Matter Mater. Phys. 1993, 47, 558-561.

(50) Kresse, G.; Furthmüller, J. Efficient iterative schemes for ab initio total-energy calculations using a plane-wave basis set. Phys. Rev. B: Condens. Matter Mater. Phys. 1996, 54, 11169-11186.

(51) Kresse, G.; Furthmüller, J. Efficiency of ab-initio total energy calculations for metals and semiconductors using a plane-wave basis set. Comput. Mater. Sci. 1996, 6, 15-50.

(52) Perdew, J. P.; Burke, K.; Ernzerhof, M. Generalized gradient approximation made simple. Phys. Rev. Lett. 1996, 77, 3865-3868.

(53) Blöchl, P. E. Projector augmented-wave method. Phys. Rev. B: Condens. Matter Mater. Phys. 1994, 50, 17953-17979.

(54) Hubbard, J. Electron correlations in narrow energy bands. Proc. R. Soc. London, Ser. A 1963, 276, 238-257.

(55) Grimme, S.; Anthony, J.; Ehrlich, S.; Krieg, H. A consistent and accurate $\mathrm{ab}$ initio parametrization of density functional dispersion correction (DFT-D) for the 94 elements H-Pu. J. Chem. Phys. 2010, 132, 154104-154122.

(56) Kümmerle, E. A.; Heger, G. The structures of $\mathrm{C}-\mathrm{Ce}_{2} \mathrm{O}_{3}+\delta$, $\mathrm{Ce}_{7} \mathrm{O}_{12}$, and $\mathrm{Ce}_{11} \mathrm{O}_{20}$. J. Solid State Chem. 1999, 147, 485-500.

(57) Capdevila-Cortada, M.; López, N. Entropic contributions enhance polarity compensation for $\mathrm{CeO}_{2}(100)$ surfaces. Nat. Mater. 2017, 16, 328-334.

(58) Henkelman, G.; Uberuaga, B. P.; Jónsson, H. A climbing image nudged elastic band method for finding saddle points and minimum energy paths. J. Chem. Phys. 2000, 113, 9901-9904.
(59) Henkelman, G.; Jónsson, H. Improved tangent estimate in the nudged elastic band method for finding minimum energy paths and saddle points. J. Chem. Phys. 2000, 113, 9978-9985.

(60) Álvarez-Moreno, M.; de Graaf, C.; López, N.; Maseras, F.; Poblet, J. M.; Bo, C. Managing the computational chemistry big data problem: The ioChem-BD platform. J. Chem. Inf. Model. 2015, 55, 95103

(61) https://doi.org/10.19061/iochem-bd-6-5.

(62) Frisch, M. J.; Trucks, G. W.; Schlegel, H. B.; Scuseria, G. E.; Robb, M. A.; Cheeseman, J. R.; Montgomery, J. A.; Vreven, T.; Kudin, K. N.; Burant, J. C.; Millam, J. M.; Iyengar, S. S.; Tomasi, J.; Barone, V.; Mennucci, B.; Cossi, M.; Scalmani, G.; Rega, N.; Petersson, G. A.; Nakatsuji, H.; Hada, M.; Ehara, M.; Toyota, K.; Fukuda, R.; Hasegawa, J.; Ishida, M.; Nakajima, T.; Honda, Y.; Kitao, O.; Nakai, H.; Klene, M.; Li, X.; Knox, J. E.; Hratchian, H. P.; Cross, J. B.; Adamo, C.; Jaramillo, J.; Gomperts, R.; Stratmann, R. E.; Yazyev, O.; Austin, A. J.; Cammi, R.; Pomelli, C.; Ochterski, J. W.; Ayala, P. Y.; Morokuma, K.; Voth, G. A.; Salvador, P.; Dannenberg, J. J.; Zakrzewski, V. G.; Dapprich, S.; Daniels, A. D.; Strain, M. C.; Farkas, O.; Malick, D. K.; Rabuck, A. D.; Raghavachari, K.; Foresman, J. B.; Ortiz, J. V.; Cui, Q.; Baboul, A. G.; Clifford, S.; Cioslowski, J.; Stefanov, B. B.; Liu, G.; Liashenko, A.; Piskorz, P.; Komaromi, I.; Martin, R. L.; Fox, D. J.; Keith, T.; Al-Laham, M. A.; Peng, C. Y.; Nanayakkara, A.; Challacombe, M.; Gill, P. M. W.; Johnson, B.; Chen, W.; Wong, M. W.; Gonzalez, C.; Pople, J. A. Gaussian 03W (Version 6.1); Gaussian Inc., Pittsburgh, PA, 2003.

(63) Ochterski, J. W. Thermochemistry in Gaussian; Gaussian Inc., Pittsburgh, PA, 2000.

(64) Li, C.; Sun, Y.; Djerdj, I.; Voepel, P.; Sack, C.-C.; Weller, T.; Ellinghaus, R.; Sann, J.; Guo, Y.; Smarsly, B. M.; Over, H. Shapecontrolled $\mathrm{CeO}_{2}$ nanoparticles: stability and activity in the catalyzed $\mathrm{HCl}$ oxidation reaction. ACS Catal. 2017, 7, 6453-6463.

(65) Leyva-Pérez, A.; Cómbita-Merchán, D.; Cabrero-Antonino, J. R.; Al-Resayes, S. I. Oxyhalogenation of activated arenes with nanocrystalline ceria. ACS Catal. 2013, 3, 250-258.

(66) Trovarelli, A.; Llorca, J. Ceria catalysts at nanoscale: how do crystal shapes shape catalysis? ACS Catal. 2017, 7, 4716-4735.

(67) Kepiński, L.; Wolcyrz, M.; Okal, J. Effect of chlorine on microstructure and activity of $\mathrm{Pd} / \mathrm{CeO}_{2}$ catalysts. J. Chem. Soc., Faraday Trans. 1995, 91, 507-515.

(68) Kepiński, L.; Okal, J. Occurrence and Mechanism of Formation of $\mathrm{CeOCl}$ in $\mathrm{Pd} / \mathrm{CeO}_{2}$ Catalysts. J. Catal. 2000, 192, 48-53.

(69) Fajardie, F.; Tempere, O.; Manoli, J.-M.; Djega-Mariadassou, G.; Blanchard, G. Ceria lattice oxygen ion substitution by $\mathrm{Cl}^{-}$during the reduction of $\mathrm{Rh}(\mathrm{Cl}) / \mathrm{CeO}_{2}$ catalysts. Formation and stability of CeOCl. J. Chem. Soc., Faraday Trans. 1998, 94, 3727-3735.

(70) De Rivas, B.; López-Fonseca, R.; Gutiérrez-Ortiz, M. A.; Gutiérrez-Ortiz, J. I. Impact of induced chlorine-poisoning on the catalytic behaviour of $\mathrm{Ce}_{0.5} \mathrm{Zr}_{0.5} \mathrm{O}_{2}$ and $\mathrm{Ce}_{0.15} \mathrm{Zr}_{0.85} \mathrm{O}_{2}$ in the gas-phase oxidation of chlorinated VOCs. Appl. Catal., B 2011, 104, 373-381.

(71) García-Melchor, M.; Bellarosa, L.; López, N. Unique reaction path in heterogeneous catalysis: the concerted semi-hydrogenation of propyne to propene on $\mathrm{CeO}_{2}$. ACS Catal. 2014, 4, 4015-4020.

(72) Zhang, P.; Sun, D.; Wen, M.; Yang, J.; Zhou, K.; Wang, Z. Hydroxyl radical promotest he direct iodination of aromatic compounds with iodine in water: A combined experimental and theoretical study. Adv. Synth. Catal. 2012, 354, 720-729. 